\title{
Evaluation of Aftermarket CNG Conversion Kits in Light-Duty Vehicle Applications
}

\section{Final Report}

C.F. Blazek, P. Freeman Rowley, J.W. Grimes

Institute of Gas Technology

Chicago, IL

NREL Technical Monitor: B. Bailey

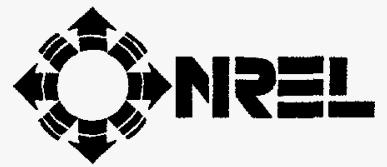

National Renewable Energy Laboratory 1617 Cole Boulevard

Golden, Colorado 80401-3393

A national laboratory of the U.S. Department of Energy

Managed by Midwest Research Institute

for the U.S. Department of Energy

Under Contract No. DE-AC36-83CH10093

Prepared under Subcontract Number YW-2-12120-1

July 1995 
This publication was reproduced from the best available camera-ready copy submitted by the subcontractor and received no editorial review at NREL.

\section{NOTICE}

NOTICE: $\quad$ This report was prepared as an account of work sponsored by an agency of the United States government.

Neither the United States government nor any agency thereof, nor any of the employees, makes any warranty, express or implied, or assumes any legal liability or responsibility for the accuracy, completeness, or usefulness of any information, apparatus, product, or process disclosed, or represents that its use would not infringe privately owned rights. Reference herein to any specific commercial product, process, or service by trade name, trademark, manufacturer, or otherwise does not necessarily constitute or imply its endorsement, recommendation, or favoring by the United States government or any agency thereof.

Printed in the United States of America Available from:

National Technical Information Service

U.S. Department of Commerce

5285 Port Royal Road

Springfield, VA 22161

Price: Microfiche

Printed Copy

Codes are used for pricing all publications. The code is determined by the number of pages in the publication. Information pertaining to the pricing codes can be found in the current issue of the following publications which are generally available in most libraries: Energy Research Abstracts (ERA); Government Reports Announcements and Index (GRA and I); Scientific and Technical Abstract Reports (STAR); and publication NTIS-PR-360 available from NTIS at the above address. 


\section{DISCLAIMER}

Portions of this document may be illegible in electronic image products. Images are produced from the best available original document. 


\section{Preface}

The National Renewable Energy Laboratory (NREL), as the field program manager for the U.S. Department of Energy (DOE) Alternative Fuels Utilization Program, is seeking methods to promote and assist the development of alternative fuels technologies for transportation applications. The focus of this study is on one such alternative fuel - compressed natural gas (CNG).

There are two major reasons for advancing alternative fuels such as CNG. The first is that alternative fuel use could potentially reduce harmful vehicle emissions. The second reason for advancing alternative fuels is that their use could displace a portion of the imported petroleum required in the U.S. by the transportation sector.

A commercial market can be developed by converting existing vehicles to allow alternative fuel use. Several manufacturers and conversion dealers/organizations have entered the market to meet the growing demand for $\mathrm{CNG}$ vehicles. The consumer desires conversion technology that delivers acceptable power, reduced emissions, fuel economy, and safety.

Some material has been published on the power, emissions, and economy of CNG-fueled vehicles. However, a comprehensive comparison does not exist. This project was conducted to provide that comparison using a single vehicle platform with equivalent state-of-the-art conversion systems. The evaluation used four different conversion systems and focused on emissions and fuel economy.

The Institute of Gas Technology would like to thank the sponsors who were responsible for funding this project: Brent Bailey and Chris Colucci of NREL, and Heide Swanson and Robert Alvey of Brooklyn Union. The project could not have been accomplished without the assistance of: David Grote and John Cappi of Northern Illinois Gas; Britt Eastman and Les Asher of Amoco; and John Baudino and Pat McPartlin of AutoResearch Laboratories, Inc. 


\section{TABLE OF CONTENTS}

\section{Introduction}

Page

Test Program $\quad 2$

Vehicle Procurement and Inspection 2

Specification of Natural Gas Composition $\quad 3$

Baseline Emission Tests $\quad 7$

Conversion System Procurement and Installation $\quad 8$

$\begin{array}{lr}\text { Mogas System } & 8\end{array}$

$\begin{array}{ll}\text { Impco System Installation } & 12\end{array}$

GFI Control Systems Inc. Installation $\quad 13$

Automotive Natural Gas Inc. ALEVS System Installation 15

Emission Test Results $\quad 19$

Conclusions 26

Recommendations $\quad 32$

References and Bibliography 


\section{TABLE OF FIGURES}

Figure

Page

1 Distribution of Specific Gravity for Natural Gas

2 Natural Gas Methane Fraction vs. Wobbe Number 5

3 Carbon Monoxide Emission Test Results 28

4 Nitrogen Oxides Emission Test Results 28

5 Total Hydrocarbons Emission Test Results 29

6 Non-methane Hydrocarbons Emission Test Results 29

7 Fuel Economy Test Results $\quad 30$

\section{TABLE OF TABLES}

Table

Page

1 Methane Fraction Analysis

2 Wobbe Number Analysis

6

3 Composition Based on Methane Mole Fraction 7

4 Composition Based on Wobbe Number 7

5 Exhaust and Evaporative Indolene Emissions Data 9

6 Mogas System Emissions Summary 20

7 Impco System Emissions Summary 21

8 GFI System Emissions Summary - 23

9 ANGI System Emissions Summary 25

10 Final Exhaust and Evaporative Indolene Emissions Data 27 


\section{Introduction}

The Institute of Gas Technology (IGT) was contracted by the National Renewable Energy Laboratory (NREL) to evaluate three compressed natural gas (CNG) conversion systems using a 1993 Chevrolet Lumina baseline vehicle. A fourth conversion system was added to the test matrix through funding support from Brooklyn Union. The objective of this project was to measure the Federal Test Procedure (FTP) emissions and fuel economy of the different conversion systems, and to compare the performance to gasoline-fueled operation and each other. Different natural gas compositions were selected to represent the 10th percentile, mean, and 90th percentile compositions distributed in the Continental United States. Testing with these different compositions demonstrated the systems' ability to accommodate the spectrum of gas found in the United States. Each compressed natural gas conversion system was installed and adjusted according to the manufacturer's instructions. In addition to the FTP testing, an evaluation of the comparative installation times and derivability tests (based on AGA and CRC guidelines) were conducted on each system. 


\section{Test Program}

A number of conversion systems are commercially available to convert gasoline-fueled vehicles to either dedicated or bi-fueled natural gas vehicles (NGVs). The objective of this study was to evaluate four state-of-the-art closed-loop natural gas vehicle (NGV) conversion systems using a range of natural gas compositions. The four kits include an Impco Adaptive Digital Processor (ADP) system, the Mogas ECOLO system, the Gaseous Fuel Injection (GFI) system from GFI Inc., and an Automotive Natural Gas Inc. (ANGI) Advanced Low Emission Vehicles System (ALEVS). Conversion system evaluation and testing included ease of installation, completeness of installation manuals, emission testing per 40 CFR Part 86, and driveability. All testing was performed with a 1993 Chevrolet Lumina equipped with a 3.1 L MPFI V6 engine. Each kit was emission tested using three different certified compositions of natural gas, representing the 10th, mean and 90th percentile gas compositions distributed in the United States.

Emission testing on Indolene was performed prior to conversion system testing to establish gasoline base emission values. Indolene testing was also performed at the end of the project to ensure that the vehicle's emissions were not altered during testing. Any variations in emissions or fuel economy related to fuel quality will be better understood as a result of the FTP emission testing program. In addition to fuel quality, this investigation also evaluated conversion system performance, both in terms of installation requirements and driveability. All procedures required to convert the gasoline fueled vehicle to compressed natural gas (CNG) are fully documented, including hardware installation, electronic hookups, and system calibration. The time required to convert the vehicle is documented along with driveability data per CRC recommendations.

\section{Vehicle Procurement and Inspection}

In December 1992, IGT acquired a new 1993 Chevy Lumina 3.1 liter MPFI V6 (VIN \# 2G1WN54T7P9146384) for the testing program as stipulated in the NREL contract. During December 1992 and January 1993, the vehicle was driven 5,000 highway miles on gasoline to ensure proper engine break-in and catalyst aging. The only maintenance performed on the vehicle was an oil change at 2,083 miles.

An inspection was performed on the Lumina at 4,803 miles to establish baseline parameters prior to emission testing and conversion to natural gas. The inspection included a compression test of the six cylinder 3.1 liter V-6. All six plugs showed minimal wear with proper gaps. Center electrode ceramics were still white and the ground electrodes had a light ashen gray appearance. No visual pitting or erosion was apparent. Each compression check consisted of 4 to 5 complete revolutions of the engine. The pressure reading was then recorded on a pressure-retaining compression checker. The compression in each cylinder was within an acceptable $10 \%$ range from highest to lowest. A hand-held Tech I diagnostic unit was connected to the ALDL link to observe vehicle operating parameters. From the unit's display the following information was recorded with the car in park and running idle. 
* Prom Calibration I.D. \# 9021

* Cooling Fan -- Off

× A.C. System -- Off

× System Voltage -- 13.9 volts

* Vehicle Speed -- 0 mph

$\times \quad$ Signal -- No

× St. Fuel Trim -- 126

* Spark Advance -- 19-20 $0^{\circ}$ BTDC

* $\mathrm{O}_{2}$ Sensor - Ranging (typical response)

* Engine Speed -- 740 RPM (near end of test)

* Coolant Temperature $-98^{\circ} \mathrm{C}\left(209^{\circ} \mathrm{F}\right)$ end of test

* IACV -- Idle Air Control Valve - 18 counts (position)

* TPS - Throttle Position Sensor Output -- 0.70 Volts

* EGR -- Elect. Exhaust Gas Recirc. -- Controlled by ECM \#1 Solenoid - off, \#2 Solenoid -- off, \#3 Solenoid -- off

* MAP Sensor -- Manifold Abs. Press. Output -- 1.58 volts

× Barometric Sensor Output -- 4.96 volts (false reading - car not equipped with this sensor)
Coolant Temp. $-88^{\circ} \mathrm{C}\left(191^{\circ} \mathrm{F}\right)$

× A.C. System Pressure -- 67 psi

$\times \quad$ RPM -- 843

× Fuel Pump Voltage -- 13.7 volts

$\times$ Knock Retard - $0^{\circ}$

* Closed Loop Operation

* Lt. Fuel Trim -- 124

* Throttle Angle - $0^{\circ}$

* Injector Pulse Width -- 1.8 milliseconds

* TCC -- Transmission Converter Clutch -- Off

* Intake air temperature $-24^{\circ} \mathrm{C}\left(75^{\circ} \mathrm{F}\right)$ end of test

The Institute of Gas Technology (IGT) then performed an emissions check at high and low idle. During the exhaust gas analysis portion of the check, the following information was observed from the display. The engine was accelerated up to 2500 RPM several times to clear the engine (sitting idle for several minutes) then allowed to idle (multiple numbers indicate range).

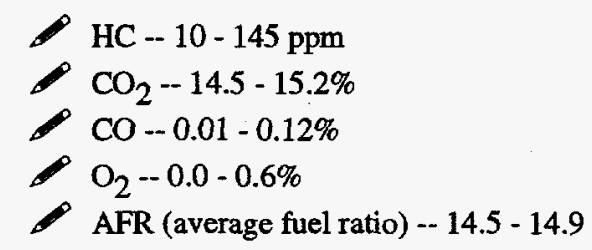

After the exhaust emission test, the car was moved to a hoist and the undercarriage and suspension were visual inspected. Everything appeared normal; all bolts tight, no leaks on the struts, etc. However, a minor leak was observed coming from the automatic transmission. Hose clamps on the cooling lines to the radiator were tightened. At this point, fluid levels in the engine, radiator, and transmission were checked. All were at a normal level.

\section{Specification of Natural Gas Composition}

Natural gas is not pure methane or a homogeneous mixture, but may vary in composition depending on location and season. These variations are produced by differences in gas composition in originating production fields and further modification due to field processing prior to transmission. Additional mixing of different gases also occurs during pipeline transmission. As a result, natural gas does not describe a single type of fuel or a narrow range of characteristics, unlike gasoline or Diesel fuel which is manufactured within certain specifications.

Fuel composition can affect vehicle emissions. In 1991, a study on natural gas composition was completed by the American Gas Association Laboratories with the Institute of Gas Technology as a subcontractor, under Gas Research Institute funding. 1 The study consisted of 6,811 natural gas samples listed by the following components: methane, ethane, propane, i-butane, n-butane, i-pentane, n-pentane, C6 and higher, nitrogen, carbon dioxide, and oxygen. This data base also contains calculations of the higher heating value, specific gravity, Wobbe number, and other values. 
The research focused on the mean average, minimum, maximum, 10th percentile, and 90th percentile gas fractions. For this NGV conversion system study, IGT established the mean, 10th percentile and 90th percentile natural gas compositions that could be encountered in the continental United States. However, information reported in the GRI sponsored study allowed for only a pseudo-composition to be developed. For example, the 10 percentile value of methane could be combined with the 90th percentile values of the other constituents for a minimum-methane concentration natural gas. For the higher end, the 90th percentile value for methane could be used with the 10th percentile values for the other gases. The rationale for this approach is that, when methane dominates the composition, the other gases would be expected to be at their lower values. However, this does not take into account that natural gas compositions are not manufactured, but occur normally with certain relationships between each of the components. As a result, IGT concluded that a more detailed review was necessary to determine representative natural gas compositions.

Two primary factors that affect emissions and directly describe the general characteristics of natural gas include the concentration of methane and the Wobbe number. The methane concentration is a good measure because it is the dominant component in natural gas. The Wobbe number is a measure of the fuel energy flow rate through a fixed orifice under given inlet conditions. It is calculated as the ratio of the higher heating value divided by the square root of the specific gravity. Figure 1 presents the range of specific gravity for natural gas distributed in the United States. A change in Wobbe number will affect the power output and performance of the engine. Variations in Wobbe number will produce similar variations in the air-fuel ratio for gas metering systems used on vehicles. Variability of this parameter will most significantly affect engines equipped with openloop controls, where the exhaust oxygen cannot be sensed and adjusted. The Wobbe number also takes into account many of the gas components because it is a bulk property.

Recognizing the importance of these factors, IGT's analysis was performed on methane concentration and Wobbe number sensitivities. The first step was to determine the minimum, maximum, mean average, median, 10th percentile, and 90th percentile values for the methane mole fraction, as shown in Table 1. As noted, the methane mole fraction ranged from $55.8 \%$ to $98.1 \%$. It should be further noted that the minimum value represents propane/air peakshaving gas. This gas is generated by many local utilities only during severe periods of high demand which typically occur during the coldest periods of the year. During mild winters these plants may not even be used and during normal winters plants may only operate 1 to 2 days per year. The equivalent values for the Wobbe number are shown in Table 2. This information is also shown graphically in Figure 2.

Having identified the methane fraction and Wobbe number values to be used, the next step was to define a suitable method of calculating the mole fractions of each of the other components. Because of the inherent variability of an individual natural gas sample, it was unlikely that a representative composition could be formulated from just the few values that fit exactly on the selected methane fraction and Wobbe number values. To select a slightly wider, more representative range of natural gas compositions at a given value, the average of each of the components was calculated considering only those samples within $1 \%$ concentration of the 


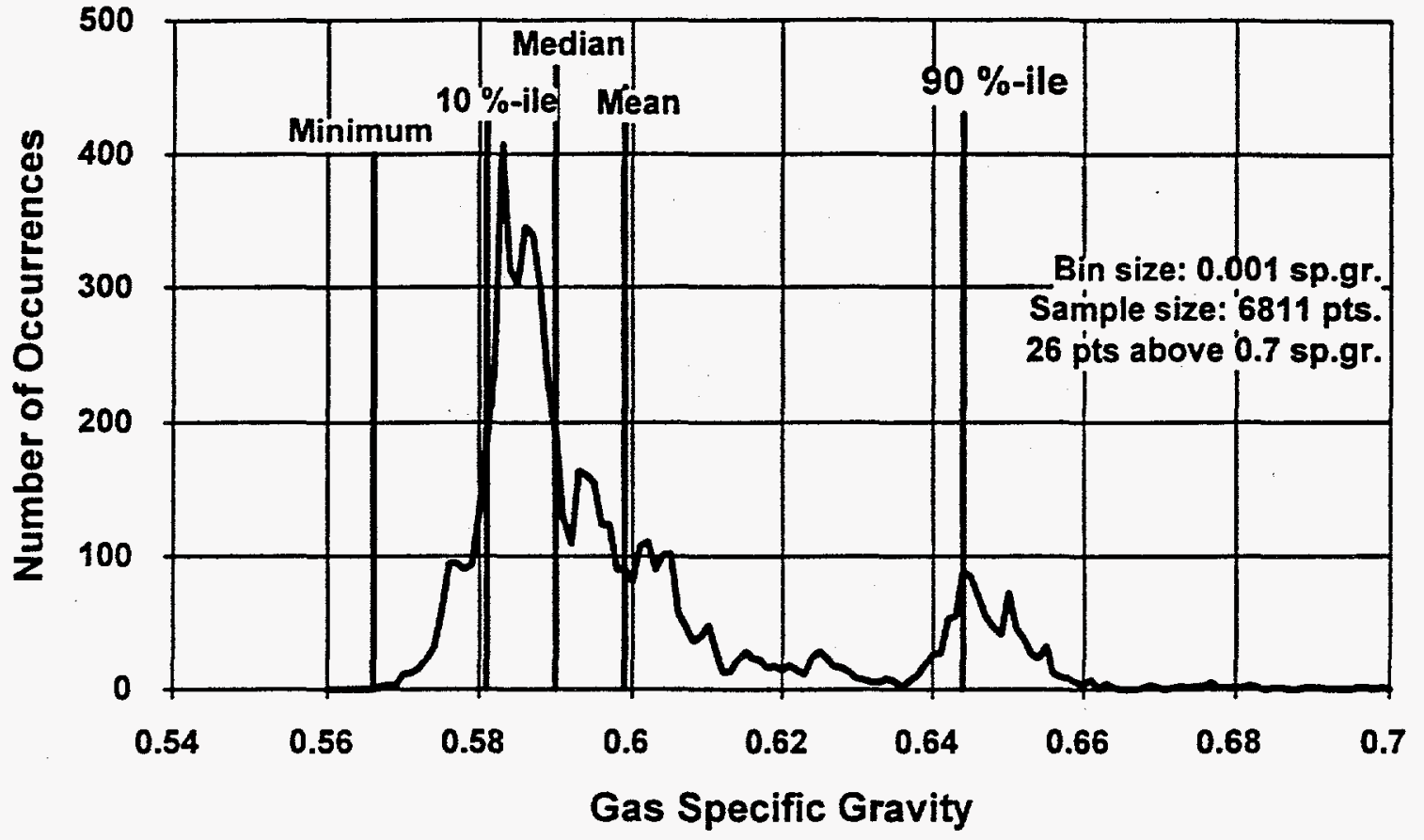

Figure 1. Distribution of Specific Gravity for Natural Gas

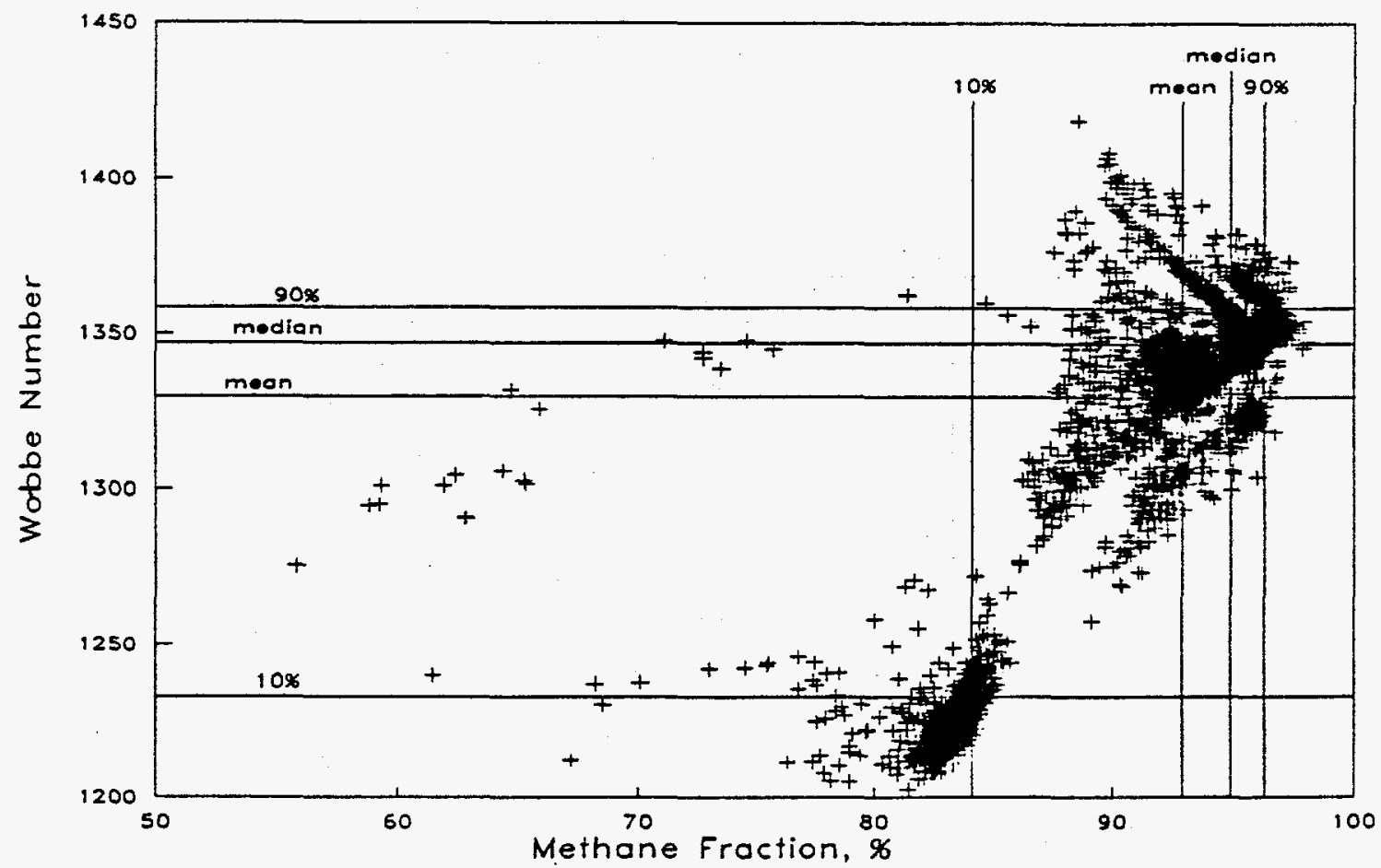

Figure 2. Natural Gas Methane Fraction vs. Wobbe Number 
TABLE 1. METHANE FRACTION ANALYSIS

$\begin{array}{ll}\text { Minimum: } & 55.8 \% \\ \text { Maximum: } & 98.1 \% \\ \text { Mean (avg): } & 93.0 \% \\ \text { Std Deviation: } & 4.5 \% \\ \text { Median: } & 94.9 \% \\ \text { 10th Percentile: } & 84.1 \% \\ \text { 90th Percentile: } & 96.3 \%\end{array}$

TABLE 2. WOBBE NUMBER ANALYSIS

$\begin{array}{lc}\text { Minimum: } & 1202.6 \\ \text { Maximum: } & 1418.7 \\ \text { Mean (avg): } & 1329.4 \\ \text { Std Deviation: } & 42.6 \\ \text { Median: } & 1347.0 \\ \text { 10th Percentile: } & 1233.0 \\ \text { 90th Percentile: } & 1358.5\end{array}$

methane fraction. For the 10th percentile, this translated into averaging the natural gas components for all samples within the methane concentration of $83.1 \%$ to $85.1 \%$. The results of this are shown in Table 3.

A similar averaging technique was completed using the selected Wobbe numbers, considering only those samples within 2 Wobbe number counts of the identified Wobbe number. These results are shown in Table 4. The near equivalency between methane concentration and Wobbe number for the natural gas composition can be seen in comparison with the resulting averages for each of the components in each of the desired ranges. For example, the methane concentration and Wobbe number for the two 10th percentile compositions are fairly close, 83.84 mole $\%$ vs. 83.96 mole $\%$ and 1229.76 vs. 1232.97 . This holds true for the other components. Although there is more variability within the mean and 90th percentile compositions, the differences are within the range of variations that may be seen throughout the year.

In speccifying the natural gas compositions to be used for emission testing, one of three criteria could be chosen. Either the Wobbe number-based values or the methane fraction-based numbers, or average of the two. Because fuel metering is a critical factor in all NGV conversion systems, both IGT and NREL agreed that the gas compositions based on the Wobbe number, as presented in Table 4, should be used for the test fuels. High pressure gas cylinders were then prepared for each of the three compositions and certified by IGT for use in this test program. 
TABLE 3. COMPOSITION BASED ON METHANE MOLE FRACTION

$\begin{array}{rcrr} & 10 \% \text {-tile } & \text { Mean } & 90 \% \text {-tile } \\ & ---- & ---- & ---- \\ \text { METHANE } & 83.94 & 93.05 & 95.98 \\ \text { ETHANE } & 5.62 & 3.47 & 2.14 \\ \text { PROPANE } & 0.99 & 0.67 & 0.36 \\ \text { I-BUTANE } & 0.10 & 0.08 & 0.07 \\ \text { N-BUTANE } & 0.13 & 0.12 & 0.08 \\ \text { I-PENTANE } & 0.03 & 0.04 & 0.03 \\ \text { N-PENTANE } & 0.02 & 0.03 & 0.02 \\ \text { C6+ } & 0.03 & 0.06 & 0.06 \\ \text { NITROGEN } & 6.28 & 1.67 & 0.53 \\ \text { CO }_{2} & 1.37 & 0.81 & 0.73 \\ \mathrm{O}_{2} & 1.49 & 0.00 & 0.00 \\ \text { WOBBE NUMBER } & 1229.76 & 1337.12 & 1349.93\end{array}$

TABLE 4. COMPOSITION BASED ON WOBBE NUMBER

$\begin{array}{rcrr} & 10 \% \text {-tile } & \text { Mean } & 90 \% \text {-tile } \\ & -1--- & -- \\ \text { METHANE } & 83.96 & 92.87 & 94.80 \\ \text { ETHANE } & 5.72 & 3.34 & 3.03 \\ \text { PROPANE } & 1.07 & 0.63 & 0.58 \\ \text { I-BUTANE } & 0.09 & 0.07 & 0.10 \\ \text { N-BUTANE } & 0.11 & 0.12 & 0.13 \\ \text { I-PENTANE } & 0.03 & 0.04 & 0.05 \\ \text { N-PENTANE } & 0.01 & 0.03 & 0.03 \\ \text { C6+ } & 0.03 & 0.05 & 0.07 \\ \text { NITROGEN } & 6.05 & 2.07 & 0.56 \\ \text { CO }_{2} & 1.40 & 0.78 & 0.65 \\ \mathrm{O}_{2} & 1.53 & 0.00 & 0.00 \\ \text { WOBBE NUMBER } & 1232.97 & 1329.15 & 1358.61\end{array}$

\section{Baseline Emission Tests}

FTP emission testing on indolene per 40 CFR Part 86 was conducted in March, 1993 on the Chevy Lumina. The 1993 EPA emission standards are $3.4 \mathrm{~g} /$ mile CO (carbon monoxide), $1.0 \mathrm{~g} / \mathrm{mile}$ NOx (nitrous oxides), and $0.41 \mathrm{~g} /$ mile HC (hydrocarbons). Two baseline indolene tests were performed with the dynamometer set for a 3,500 pound inertia and $6.0 \mathrm{ahp}$. The vehicle odometer read 6,410 miles. The test results are presented in Table 5. As can be seen from the test results, the vehicle passed the exhaust emissions and Shed test. Weighted total hydrocarbon values were 0.23 and 0.27 , carbon monoxide 2.74 and 2.84 , nitrous oxides 0.48 and 0.49 , carbon dioxide 489 
and 491 , respectively reported in grams per mile, with fuel economy for both tests at $18.0 \mathrm{mpg}$. The Shed test results were 0.34 and 0.39 grams respectively.

\section{Conversion System Procurement and Installation}

Compressed natural gas conversion systems are not readily available for every vehicle sold in the U.S. In reality, each system is somewhat "customized" for a specific vehicle or range of vehicles based on factors such as vehicle manufacturer and engine family. Many conversion system providers do not have the resources to modify their systems for each type of vehicle or provide sufficient documentation for installation on a specific vehicle platform. Changes in emission standards and vehicle platforms also create a dynamic situation in terms of conversion system modifications, and in some cases changes to the suppliers themselves. This became readily apparent when IGT attempted to purchase one of the recommended conversion systems from Garretson Equipment Co. At the start of this project, Garretson was acquired by MESA Environmental and after the acquisition the system was withdrawn from the market. The four systems selected for the study were the Impco ADP system, Mogas ECOLO system, the GFI system from GFI Control Systems Inc., and the ANGI ALEVS system.

\section{Mogas System}

The first kit installed was the Mogas system. The Lumina test platform was equipped with air conditioning, cruise control, power steering, and an ABS braking system. These subsystems are mentioned because their presence in the engine compartment complicated the installation procedure by occupying nearly all of the available space that might normally be used for mounting the conversion kit components. As a result of the severe space limitations, certain elements of the original engine compartment layout were moved to make room for the conversion components. Installation of the hardware under the hood also required consideration of heat dissipation from exhaust manifolds, engine block, radiator and transmission. Several components in the conversion kit (i.e., electronic brain box, regulators, and mixer) may suffer in performance if mounted close to these heat sources. The conversion kit hardware must also be located for adjustment access, filling, and wire routing to engine sensors located around the engine compartment. As a result, certain sensor inputs for the conversion did not have adequate length wire leads, which necessitated splicing and soldering additional wire lengths to reach the sensors in question. For this reason IGT elected to extend the leads for the MAP (Manifold Absolute Pressure) sensor, knock sensor, fuel injector trigger, TPS (Throttle Position Sensor), 12 volt supply (ignition key actuated), spark plug inductive wrap and digital EGR input.

Conversion of the Lumina to a bi-fueled vehicle required locating and mounting the 3,000 psig service pressure rated storage tank. The compressed natural gas tank was firmly mounted in the trunk while the existing gasoline fuel storage/delivery system was left intact and undisturbed. The availability of different sizes and shapes in tanks is still limited and the tank chosen for the Lumina was supplied by Mogas. This tank, manufactured by SCI, is approximately 18 " diameter by $36^{\prime \prime}$ long. Because of the tank's physical size it would not fit between the strut towers in the trunk (a good location on most cars) and still allow easy access to the valving for quick connect of the fuel storage bottles and gas sampling port. Therefore, the tank was mounted with the supplied 
TABLE 5. EXHAUST AND EVAPORATIVE INDOLENE EMISSIONS DATA

Test Fuel

Vehicle Odometer, miles

Exhaust Emission Results

Cold Transient, grams

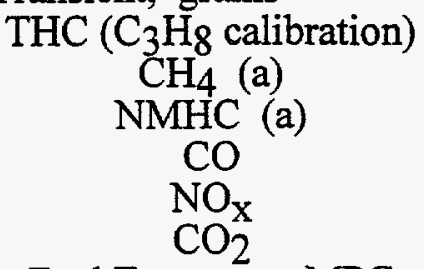

Fuel Economy, MPG

Cold Stabilized, grams

THC ( $\mathrm{C}_{3} \mathrm{H}_{8}$ calibration)
$\mathrm{CH}_{4}$ (a)
$\mathrm{NMHC} \mathrm{(a)}_{\mathrm{CO}}$
$\mathrm{NO}_{\mathrm{x}}$
$\mathrm{CO}_{2}$

Fuel Economy, MPG

Hot Transient, grams

$$
\begin{gathered}
\text { THC ( } \mathrm{C}_{3} \mathrm{H}_{8} \text { calibration) } \\
\mathrm{CH}_{4} \text { (a) } \\
\mathrm{NMHC}^{(\mathrm{a})} \\
\mathrm{CO} \\
\mathrm{NO}_{\mathrm{x}} \\
\mathrm{CO}_{2}
\end{gathered}
$$

Fuel Economy, MPG

Weighted Total, grams / mile

THC $\left(\mathrm{C}_{3} \mathrm{H}_{8}\right.$ calibration)

$\mathrm{CH}_{4}$ (a)

NMHC (a)

$\mathrm{CO}$

$\mathrm{NO}_{\mathrm{x}}$ $\mathrm{CO}_{2}$

Fuel Economy, MPG

Shed, grams

Diurnal

Hot Soak

Total
Indolene Indolene

6410

6429

2.65

0.22

2.40

23.24

4.25

1741

17.9

3.15

0.26

2.85

26.97

3.95

1767

17.6

0.34

0.12

0.20

4.70

1.14

1992

17.9

0.25

0.12

0.11

4.32

1.21

2004

17.0

0.45

0.74

0.13

0.14

0.29

0.57

8.99

1.22

1536

1.02

1533

20.5

20.5

0.23

0.27

0.04

0.19

0.22

2.74

2.84

0.48

489

18.0

0.49

491

18.0

$\begin{array}{ll}0.12 & 0.20 \\ 0.22 & 0.19 \\ 0.34 & 0.39\end{array}$

(a) CNG Tests: Methane concentration for NMHC (non-methane hydrocarbon) calculation is based on GC speciation analysis. 
mounting brackets in the middle of the trunk area. Heavy gauge steel retaining brackets were then drilled and bolted through the floor. Two 2-inch-diameter holes were also drilled for the supply line and vent hole. The vent line allows any gas leaks collected by the bags surrounding the tank ends to vent directly to the outside of the vehicle as opposed to venting in the closed trunk space. These bags were sealed to the ends of the tank using a vinyl adhesive and to the vent hole with worm gear hose clamps.

Next, IGT located an area under the hood to mount the 3-stage regulator, Computer Support I (electronic brain box), solenoid, and relay. Space existed under the windshield washer reservoir where the battery was located. Removal of the reservoir and battery provided enough room on the driver's side to mount everything but the mixer. A vertical bracket was fabricated to mount the 4stage regulator and holes were drilled in the radiator support for the computer support module. At the same time a battery box, cable, and side terminal battery connections were procured for relocating the battery to the trunk between the strut towers. Holes for venting and mounting the battery box were drilled through the trunk floor.

IGT then mounted the natural gas tank fuel gauge and switch and Lambda Fuel Control Processor $\left(\mathrm{O}_{2}\right.$ sensor meter) on the dash. Wiring looms were installed under the dash and through a slit made in the plastic boot that surrounds and protects the steering wheel shaft. Wiring was pulled through the dash to the computer control per the Mogas wiring schematic. The positive and negative battery cables were routed beneath the car to the battery box. New side terminals were attached to the cable ends and each end was attached to the appropriate existing battery cable and battery in the trunk. All connections were covered with hose and taped to insulate from unintentional grounding.

With the tank mounted, a 1/4" (0.035 wall thickness) pressurized supply line was routed from the regulator back to the tank beneath the car. Mounting clamps for the $1 / 4$ " tube and battery cables were drilled and installed on approximately 24 " centers. Swagelock tube to $1 / 4$ " pipe adapters were installed on the Mogas 3-stage regulator inlet. A tee and sample valve with a cap for gas sampling and venting of the pressurized line (installed for test purposes only) were also installed. A bracket was fabricated for the Hanson quick disconnect fueling receptacle and check valve. The injector cut-off relay was also installed on this brace.

Splices were then made in the coolant water supply and return lines to the heater core for the HVAC system. These hoses were routed and connected to the Enviro-Cap on the regulator and attached with worm gear clamps provided with the kit. IGT also attached the vapor supply hose to the regulator and routed the hose and mounted the power valve with vacuum control. The hose from the power valve was routed to the venturi-type mixer. The mixer was then mounted to the intake plenum with a hose provided with the kit. With the mixer installed, the connection between the air filter box and the mixer was completed. This was accomplished by cutting the OEM rubber hose from the air filter box to a shorter length and clamping the hose to the mixer. With this task finished, the hardware installation for the system was completed, leaving only the wiring connections and routing of the sensor wires. 
Using the system diagram and the Mogas Computer Support 1 (Autotronic Controls Corp.) diagram, the selector switch/fuel gauge and the Lambda fuel control processor were connected. Additional wiring connections to the existing Lumina loom included connection of the MAP sensor, TPS, knock sensor, injector control, +12 volt hot ignition on, digital EGR, $\mathrm{O}_{2}$ sensor, spark signal wire, Lambda control, and selector switch / fuel gauge. With the wiring and vacuum connections complete, the final battery connections were made and the ignition turned to "ON". Electrical checks were made to see if everything was connected properly.

With the wiring completed and checked, the tank was filled with natural gas to systematically higher pressure levels while checking for leaks. No leaks were found so the tank was pressurized to 3,000 psig (full) and no leaks were detected. With the engine operating on gasoline, the NG system was activated. With a slight hesitation at switch over, the engine ran smoothly on natural gas. With the car running, set-up and fine tuning were performed. Set-up required a digital high input impedance (10 MOHM) voltmeter to observe voltage output from the $\mathrm{O}_{2}$ sensor during gasoline operation. According to the set-up instructions $\mathrm{O}_{2}$ sensor voltage output was observed while on gasoline during idle, part throttle cruise, and maximum voltage during a hard acceleration. Observed voltages at idle were low at $0.03 \mathrm{~V}$ to $0.08 \mathrm{~V}$. Under mild acceleration and part throttle cruise, voltages increased to 0.4 to 0.8 , toggling between those amounts at a steady cruise. Under hard acceleration, sensor voltage increased to as high as $0.92 \mathrm{~V}$. During subsequent drives these voltages were typical of all those observed with toggling voltages between 0.2 and 0.8 . When the switch was made to CNG, voltages at idle became very high, typically in the +0.88 range, indicating a rich idle. Adjustment of the positive idle screw could not reduce the voltage below 0.8 volts without stumbling and dying. At part throttle (or anything off idle) voltages would drop to below 0.1 , typically between $0.02 \mathrm{~V}$ and $0.05 \mathrm{~V}$, indicating a very lean condition. No amount of adjustment to the power valve screw would raise this voltage to a level observed while on gasoline. Many checks on the system and adjustments to the positive idle screw, sensitivity screw, and/or the power valve did not change this output significantly.

After several attempts to correct the problem, the Mogas technical representative was consulted and suggested checking several items. After making the suggested checks, nothing was found, yet the system was performing adequately. Noticeable surging occurred when any attempt was made to open the power valve (richer). If the valve was closed, the engine would lose power, stumble and/or die. After further discussion with Mogas, it was suggested that as the $\mathrm{O}_{2}$ sensor readings were still questionable, the problem might be with the $\mathrm{O}_{2}$ sensor not responding to the natural gas combustion exhaust temperature. A replacement $\mathrm{O}_{2}$ sensor was procured and installed. When the engine was fired after replacement of the $\mathrm{O}_{2}$ sensor, idle $\mathrm{O}_{2}$ sensor voltage was 0.15 volts and at cruise between 0.2 volts and 0.8 volts, indicating that it was now "toggling" normally unlike previously observed on natural gas. It appears the original $\mathrm{O}_{2}$ sensor would not respond to the cooler combustion temperatures of natural gas, or was perhaps not compatible with natural gas. In any case, with the $\mathrm{O}_{2}$ sensor voltage in range, final adjustment to the power valve and positive idle adjustment were made to complete the installation.

In general, the Mogas manual was sufficient to install the system. However, the manual presented in the appendix is more generic. It did not include any vehicle specific information, which required frequent reference to the shop manual for the Lumina. At this point, IGT conducted a 
driveability test following the CRC Report No. 577 "1990 CRC Driveability Workshop" recommendations published in October $1990 .^{2}$ The vehicle equipped with the Mogas system started on the first try and no faults were recorded. Installation time for the basic system components (such as fuel lines and tank) was approximately 8 person-hours. Installation time for the Mogas specific components required an additional 24 person-hours. These times reflect the component placement difficulty in the Lumina engine compartment.

\section{Impco System Installation}

The second kit installed on the vehicle was the Impco ADP conversion system. This kit consisted of the following components:

$\begin{array}{llll}\times & \text { Impco carburetor with feedback gas valve } & \times & \text { Fuel control valve (FCV) } \\ \times & \text { Impco converter } & \times & \text { Impco VFF30 fuel lock } \\ \times & \text { High-pressure regulator (heated) } & \times & \text { Vacuum control solenoid (VCS) } \\ \times & \text { Potter Brumfield 2 pole-single pull (NC) relay } & \times & \text { 2PDT toggle switches } \\ \times & \text { High-pressure gauge with pressure signal outputs } & \\ \times & \text { Impco Model AFCP-1 fuel control processor(FCP) } \\ \times & \text { Manifold vacuum switch (3-wire) - not used (for air pump equipped or turbo charged engines) } \\ \times & \text { Allison magnetic mount pressure signal compensator/isolator for dash gauge (not installed) }\end{array}$

The kit also included all the hardware for installing and mounting the 1/4-inch high-pressure supply line and coolant supply and return splices, as well as a Hansen quick disconnect (male only) and 1/4-inch male pipe adapters, elbows, and tees. The wiring came with connectors, splices and spade lugs to complete the electrical tie-ins and signals to the FCP from the existing on-board ECM signal inputs such as $\mathrm{O}_{2}$ sensor, ICM (ignition control module, distributorless ignition), and tach terminal.

Mounting the hardware of the Impco system required considerable effort. Since the Lumina was previously equipped with the Mogas system, many of the inputs for this system were tagged and wrapped for future use because they were not required for the IMPCO system. The space left by relocating the battery was cleared of the Mogas hardware and electronics and utilized for the mounting of the converter (2nd-stage regulator), 1st-stage high-pressure regulator, fuel lock/filter, FCV, and VCS. All items were drilled and mounted with bolts or self-tapping screws to the bulkhead of the strut tower brace. High-pressure hoses were fabricated to connect the regulated side of the high-pressure regulator to the fuel lock/filter and from the fuel lock to the converter.

With the pressure control hardware mounted, it became apparent that the OEM air filter box would not fit to allow a transition/adapter to the Impco carburetor. After several attempts to position the carburetor with various adapters, the air filter box was removed and an air cleaner was fabricated. IGT/Northern Illinois Gas Co (NIGAS) also fabricated a mounting bracket for the carburetor as well as a transition piece to the carburetor from the OEM air filter box rubber hose to the fuel intake plenum. This hose was cut at the neck to reduce its diameter to approximately $2-5 / 8$-inch to mate to the Impco carburetor. A filter element approximately 6 inches in diameter was then placed over the inlet side of the Model 125 air valve carburetor and held with a round aluminum sheet and long 1/4-inch, 20 stud. It should be noted that because of the confined area for installing hardware on this particular vehicle, the additional steps taken would not necessarily be required on 
other vehicles or engine/drive train combinations. The fuel control processor was wired and hooked up as installation continued. According to instructions, the fuel control processor was installed in the passenger compartment away from heat and moisture. The wiring (schematic attached) was then pulled though the dash to the engine compartment.

Next, the 2-pole, single-pull relay wiring was installed. Using the 2-pole, double-throw toggle mounted on the dash, a $+12 \mathrm{~V}$ supply was routed to the center connection, and the $+12 \mathrm{~V}$ switched supply for the fuel control processor was connected. At this point a wiring error was made based on the system schematic. A relay was attached on the opposite side of the toggle switch. However, this relay was found to be normally closed. When $+12 \mathrm{~V}$ was applied to the relay it would open the circuits. The instructions did not clarify this nor were the instructions explicit about installation. The relay controlled both the fuel pump circuit and the injector circuit. However, with the relay power on, the other side of the 2-pole, double-throw toggles would shut off the circuits because of the NC contacts (open on energization). After attempting to switch from natural gas to gasoline, the engine would die. At the same time a 20-amp fuel pump/ECM fuse blew and set a fuel pump relay diagnostic code. After careful examination, it was decided to not cut off the fuel pump because a parallel circuit through the oil pressure switch would keep the pump running once the oil pressure switch received $4 \mathrm{psi}$ from starting or the running engine. This also kept the diagnostic code from registering. As a result, the $\mathrm{NC}$ relay was placed on the natural gas-powered side of the toggle. In this manner, the fuel injectors were off whenever the system was toggled to natural gas and on in all other positions. However, for long-term use, a better switching system should be considered to allow for turning off power to the injectors and fuel pump without triggering a diagnostic code.

With the initial installation problem solved, final assembly was completed by installing the vacuum hose connections for the fuel control valve and the vacuum control solenoid. The vacuum source was drawn from the air valve vacuum ports on the Impco carburetor and not from manifold vacuum. With the system installation complete, the system was pressure- and leak-checked. Minor leaks were discovered, tightened, and corrected.

Once the system check was completed, a test drive and dynamometer set-up were performed using a Snap-On analyzer for ECM parameters. The power valve and idle adjustment on the Impco carburetor were adjusted. Adjustments were made to minimize tailpipe emissions (through the converter) without sacrificing driveability. During our driveability test, the vehicle started within 5 seconds, and recorded no faults during the test. The manuals provided by IMPCO as presented in the appendix were generic in nature and not very detailed. Thorough knowledge of the vehicle aided in the installation. In addition to the 8 person-hours for the basic hardware, the IMPCO specific equipment required approximately 24 additional person-hours to complete the conversion.

\section{GFI Control Systems Inc. Installation}

The third system installed on the vehicle was the GFI (Gaseous Fuel Injection) system marketed by GFI Control Systems, Inc.(GFI). The GFI system consists of the following components:

* Metering valve with enclosed electronics

$\times \quad 5$ mounted solenoids and 2 injectors $\times \quad$ Attached wiring harness

× Internal relief valve (set at 175 psig) 
x Low-pressure filter and brackets

x Tube and hose fittings

$x \quad$ LED dashboard light and switch

x Manifold skin temperature sensor

$\times \quad$ Heated $\mathrm{O}_{2}$ sensor

x High-pressure solenoid

$x$

Single-stage regulator
* Spray bar

x Relay hamess with fuse holders

x Intake air sensor (IAT)

x Vacuum fittings and connectors

x Wire crimp lugs (male only - GFI style)

× Pressure sensor for connecting to the OEM fuel gauge

The system manual and kit was thorough and complete. IGT did have to make up two connectors for the heated $\mathrm{O}_{2}$ sensor voltage source. Questions were quickly answered by the GFI technical representative. Mounting the hardware for the GFI system was relatively easy because there were only two pieces of equipment, the regulator and metering valve. These were mounted in the area previously occupied by the battery and windshield washer reservoir. The relays and fuse holders were also mounted along the fender panel in this area. Coolant supply and return line splices made during the previous conversion were connected to the regulator, as well as the $1 / 4$ inch SS tube CNG high-pressure supply line. Hoses were then fabricated, cut, and end fittings crimped for the pressurized supply to the metering valve. The $\mathrm{CNG}$ filter between the regulator and metering valve was also mounted and hose ends prepared and crimped using NIGAS hydraulic hose crimping tools. Next, the spray bar was mounted in the rubber intake air hose leading from the air cleaner box to the intake plenum. The vapor hose from the metering valve was cut to length, installed and clamped. Next, Teflon tape was used to install the MAP take-off. This required calibration to the MAP sensor vacuum source while attached to the metering valve barbed connection.

With the hardware located and mounted, the wiring harness from the metering valve and regulator was evaluated, taped and connected per the installation instructions. This became the major task in the installation, as the harness has approximately 50 wires with 15 separate connectors, as well as 3 relays with fuse holders, switch and indicator LED harness. There are 4 ground wires and separate ground for the $\mathrm{O}_{2}$ sensor (block ground) signal and $\mathrm{O}_{2}$ sensor heater, plus $12 \mathrm{~V}$ supply and ground (chassis). Most of these connections required fabricating mating connectors and kitsupplied connectors, lugs, seals and keepers. Fabrication required crimping lugs on the wire with special wire crimpers. Each wire and lug was then soldered to ensure a solid connection. After soldering, the weather-pak seals were crimped in the connector. Once all the wires and seals were inserted and seated into each connector, the wire keeper was installed and the connector installed to its mating half. With the number of wires involved, this became a major task requiring a considerable amount of time. Time was required not only to make up the connectors, but also to locate the signal source or input required in the OEM wiring harness and make up the tap service ( 1 connector) or the intercept splice ( 2 connections). All splices were then soldered for optimum conductivity and taped for insulation. It should be noted that GFI recognized the problems encountered with wiring the harness hook-up. IGT was informed that future kits will be supplied with more complete wiring harnesses and connectors to substantially reduce installation time. Because of the wiring difficulties, this system took the longest to install. In addition to the basic 8 person-hours, the GFI specific components required an additional 28 person-hours to completely install and calibrate. 
With the wiring installed, final connections to the spray bar, metering valve and regulator were made, checked under pressure, and leaks were fixed. The serial port connector on the GFI unit was used to link a laptop PC to the GFI electronics for setup and calibration. Using software provided by GFI for the 1993 Lumina platform (GFI developed the 1993 Lumina version ahead of normal schedule specifically for this project), IGT performed the field calibration of the system. During calibration the fuel gauge was also calibrated for linking the tank pressure transducer to the OEM dash gauge. Fuel composition was also programmed into the calibration software based on data supplied by NIGAS. Calibration was completed and the Lumina was road-checked for any obvious problems. The system was then subjected to the CRC driveability test by IGT and it passed with no faults.

\section{Automotive Natural Gas Inc. ALEVS System Installation}

Testing of this fourth conversion system was sponsored by the Brooklyn Union Gas Co. As part of the requirement to obtain the ALEVS system for this project, IGT became an "authorized" installer which included "factory" training and the purchase of a "dealer" ALEVS installation package. The dealer package included the following items:

Communicator - Data Link DB9

LEV Orifice Kit, 1-24 Pcs.

Adapter Modem Link Kit

Vehicle Set-up Computer Hardware Assembly (configured with 1993 Lumina files)

LEV Dealer Modem Kit

Not included in the initial shipment were the "Verifier Box - LEV Dealer V012" and the "Storage Case - ALEVS Installation."

The ANGI ALEVS system consists of the following components:

High-pressure regulator

Electrically-controlled fuel cut-off relays

Aluminum mixer

Vapor hose

Tubing

Brackets

Wire connectors

Electrically-controlled power valve

× Pressure gauge

* OEM injector cut-off relay,

$\times \quad$ ANGI ALEVS ECM (brain box)

$x \quad$ Wiring loom

x Interchangeable sized orifice in the vapor hose

× Tube fittings

x Mounting hardware

× Two-stage low-pressure regulator assembly

* $\quad 2$ pole double throw rocker control switch

× Autotronic Controls Corp. Super Fix I (map sensor controlled - Part \#8789-6M) for sensor signal processing

* Gas gauge compensator and signal processor (for pressure gauge signal)

The kit was complete except for detailed installation instructions and detailed wiring diagrams. Attempts to obtain further information from ANGI were unproductive so IGT proceeded with the installation despite the missing information.

After IGT progressed as far as possible with the installation based on available documentation, it was decided to have an ANGI technical representative provide on-site training to help complete the conversion. However, when the ANGI technical representative arrived, he assisted only in 
connecting the remaining wires for the circuits that were lacking schematics. No new instructions or documentation were provided.

Installation began with the removal and tagging of wires from the inputs of the GFI system. Because of the complexity of the GFI kit and the number of inputs, removal took about 6 hours. With this system removed and all wires reconnected, terminated and tagged, installation began on the ANGI system. The high-pressure regulator, 2-stage regulator, and CNG fuel cut-off relay came assembled on a common bracket. This assembly was mounted in the engine compartment in the battery/windshield washer reservoir. Brackets supplied with the kit were bent, holes drilled, and the assembly mounted. Next, the OEM rubber hose from the air filter box to the plenum was modified slightly and previous holes in the hose were taped to prevent air leaks. The hose was forced to the mixer and clamped. The mixer fit the oval opening of the OEM plenum perfectly and was held in place by 3 Allen Head set screws. Once the hose, air filter box, and mixer were ready for final installation, the mixer was sealed to the plenum with $\mathrm{O}_{2}$ sensor safe RTV to prevent air/NG leaks.

Next, the 1/4-inch tube NG supply line was rerouted to clear the two-stage regulator. Once the supply line was installed and connected, the Autotronic control brain box was installed. The brain box wire harness was attached to the map sensor, Knock sensor, a +12 volt source, $\mathrm{O}_{2}$ sensor, and the brown wire in the ANGI ALEVS wiring loom. The green and gray wires were left unattached (not necessary for this installation according to ANGI). This completed the Super Fix I installation. Next, the ALEVS brain box loom was run through the dash and the ANGI ECM brain box mounted to the underside of the dash. (No room in the dash for the ECM.) Finally, the wires were connected per the written instructions in the ANGI installation manual.

With the wiring connected, a problem with the ignition signal was corrected by setting the dip switches in the ALEVS ECM. The fuses were then installed. The rocker switch was mounted on the underside of the dash and the ALEVS ECM plugged into the harness. Routing the wires and loom under the dash was then finished. The compensator and fuel injector cut-out relay were connected and insulated with the assistance of the ANGI technical representative. The wiring for the fuel gauge compensator was attached to the wire from the OEM sending unit to the fuel gauge and attached to the under dash rocker switch. The fuel injector cut-out relay wiring was connected to the injector wiring to cut out the OEM injectors when operating on natural gas. A +12 VDC supply and ground were also run to completed the wiring sequence. The amount of time to install the entire wiring system was approximately 15 hours. If a detailed wiring schematic had been avaitable from ANGI, this time would have been considerably less.

After connection of the final wiring, set-up began with the service representatives computer (similar to the one provided in IGT's "dealer kit"). However, the ANGI service representative had an earlier version of the vehicle software (identical to that provided in our kit), and based on this software the technical advisor determined that the ALEVS ECM (brain box) and/or power valve was not working properly. This problem could have been avoided if a color-coded wire schematic of the circuits and hardware had been provided with the kit, as well as updated software for training and set-up, and vehicle-specific information. 
In addition to initial problems with the ECM and power valve and the delay they caused, most of the time was spent on the set-up. Set-up requires following a 5-step procedure on the set-up computer. The five steps have to be satisfied before set-up is considered complete. They are listed below:
1. Initial Set-Up
2. $\mathrm{O}_{2}$ Sensor Warm-Up
3. Map Calibration
4. Block Learn
5. Idle Set-Up
6. Sensor Diagnostics

- Completed

- Completed

- Completed

- Completed

- Completed

- Trouble Shooting

1. Initial set-up required analysis of the car's exhaust by a 4-gas analyzer. $\mathrm{CO}$ emissions were to be set at $1.0 \%$ to $2.0 \%$ at $3000 \mathrm{RPM}$ (no load) and $0.3 \%$ to $0.8 \% \mathrm{CO}$ (at idle). This was accomplished by manually changing the fuel metering value (FMV) to $100 \%$ open and changing orifices until $\mathrm{CO}$ readings were in the range at $3000 \mathrm{RPM}$. Further adjustments ere made by correcting the 2-stage regulator's idle screw at idle. This process became tedious as the 4-gas analyzer used sampled gas after the converter. Readings were not stable or repeatable so the unit was set to the lowest $\mathrm{CO}$ reading possible without affecting driveability.

2. $\mathrm{O}_{2}$ sensor warm-up required the car run at $3000 \mathrm{RPM}$ while the $\mathrm{FMV}$ stroked through $1 \%$ changes in valve position. The computer would then display whether the orifice was causing rich or lean exhaust. The orifice would then be regulated accordingly and then start again at the beginning. Several times the orifice was changed from 3/8" (24/64") to $23 / 64$ " (one increment) only to have the $3 / 8$ " too large (too rich) and a smaller orifice required. When the 23/64" was installed, it was too small (too lean), and a larger orifice was required (the weather was $90^{\circ} \mathrm{F}+$ and $90 \%+$ humidity). The next day when testing continued, the 23/64" orifice was too rich and the 22/64" (11/16") was too lean (weather was $75^{\circ} \mathrm{F}$ with lower humidity). The $22 / 64^{\prime \prime}$ orifice was finally chosen as it satisfied the $\mathrm{O}_{2}$ sensor warm-up step.

3. Map calibration instructed acceleration to 3,000 RPM with immediate release. No errors or problems with this step were encountered.

4. Block Learn instructions required a 3,000 RPM hold while the FMV stepped at $1 \%$ intervals through the valve stroke while the monitor displayed rich, lean, or stoiciometric readings from the $\mathrm{O}_{2}$ sensor. If something was not correct, a warning would display that the orifice was too large or too small, and to start again. After 2 days, this step was completed using the 11/32" orifice.

5. Idle Set-Up instructions required that the car idle while the valve percent opening changed. A warning would appear that the idle was too rich and to adjust idle accordingly. This was also adjusted for two days until lean readings were obtained through the entire test although the computer erroneously still said the idle was too rich. This error message continued even when the computer registered all steps as complete. 
6. Sensor Diagnostics was used to monitor the system and check for out-of-range or malfunctioning sensors. This test was used while driving the car and during troubleshooting.

Despite complete verification of set-up by the computer, IGT was still concerned that the system was not set up properly. FTP screening tests on the vehicle conducted at the Amoco research facility verified that installation was not performed properly as the vehicle stalled during testing. ANGI requested that the vehicle be brought to their facility in Wisconsin to conduct further work.

All work performed on the vehicle at ANGI was conducted in the presence of the IGT engineer who was involved in all of the conversions. Work began by drilling a hole in the exhaust pipe, after the $\mathrm{O}_{2}$ sensor but before the catalytic converter, for exhaust gas sampling during setup (this was not previously performed by IGT). Initially, the $\mathrm{HC} / \mathrm{CO}$ analyzer indicated the car may have been set up rich although this was not the case. During setup procedures, the fuel metering valve (FMV), a motor-operated butterfly valve, would not visually initialize or open and close with power on. The IGT engineer removed the valve and a spare valve was installed but the same problem occurred. The original valve showed normal operation during bench testing. Next, the ANGI "brain box" ECM was removed and bench-checked and again checked out correctly. Next, a device called a verifier was installed in place of the ECM (back-ordered at the time of our "dealer" kit purchase). The verifier indicated all wiring was installed properly and all connections were good. However, something was still causing the FMV to respond improperly.

Past problems of this nature have been observed by ANGI and have been traced to faulty wiring or shorts in the ANGI wiring loom. IGT and ANGI personnel initiated continuity checks on the loom connectors between terminals. Most terminals showed no continuity, or $10 \mathrm{ohms}$ resistance or more, probably in the coils or relays in the circuitry. However, two adjacent terminals had continuity where there should not normally have been continuity. These terminals were part of the FMV stepping motor control circuitry. It was then decided to disassemble the connector at the ECM. Upon closer inspection of the disassembled connector, a strand of wire from one crimped terminal had been inserted into a corresponding terminal during assembly. After the offending strand of wire was removed, the system was reassembled. ANGI wanted to repeat the setup because this strand of wire would have affected FMV operation. Originally, it was felt that setup was rich based on analyzer output. However, setup using the laptop computer and analyzer resulted in 3 steps (1/64" at a time) up to $25 / 64$ " in orifice size - richer from the setup IGT had established with NIGAS. This brought the CO into a range of $0.55 \%$ to $0.75 \%$, which is what was needed during setup. From this point, setup proceeded as described previously. The car was test driven and the engine loaded with accessories to try to stall the engine. No stalling or hesitation occurred, and IGT determined that the system was finally ready for emission testing. In addition to the 8 person-hours for basic hardware installation, the ALEVS system specific components required approximately 20 person-hours to install. Installation time was further extended by the time required to trouble-shoot the preceding problems. 


\section{Emission Test Results}

All emission tests were performed at the AutoResearch Laboratories per 40 CFR Part 86 . The dynamometer was set for a 3,500 pound inertia and $6.0 \mathrm{ahp}$. The test results for the Mogas system are presented in Table 6 for the three different gas compositions. For the mean natural gas composition fuel, the weighted total hydrocarbons (using a methane calibration) were 1.41 and 1.40 , methane was 1.40 and 1.42 , non-methane hydrocarbons were reported as 0.16 and 0.11 , carbon monoxide 0.39 and 0.19 , nitrous oxides 0.85 and 0.90 , and carbon dioxide 363 and 357 , respectively reported in grams per mile. Fuel economy for the tests were $18.9 \mathrm{mpg}$ and $19.1 \mathrm{mpg}$, respectively. For the 90 th percentile natural gas composition fuel, the weighted total hydrocarbons were 1.28 and 1.37 , methane was 1.22 and 1.34 , non-methane hydrocarbons were reported as 0.16 and 0.09 , carbon monoxide 0.59 and 0.28 , nitrous oxides 0.79 and 0.83 , and carbon dioxide 351 and 355, respectively reported in grams per mile. Fuel economy for the tests were $19.2 \mathrm{mpg}$ and $19.0 \mathrm{mpg}$, respectively. For the 10 th percentile natural gas composition fuel, the weighted total hydrocarbons were 1.72 and 1.98 , methane was 1.66 and 2.00 , non-methane hydrocarbons were 0.17 and 0.18 , carbon monoxide 0.12 and 0.13 , nitrous oxides 1.03 and 1.01 , and carbon dioxide 355 and 359 , respectively reported in grams per mile. Fuel economy for the tests were $20.7 \mathrm{mpg}$ and $20.4 \mathrm{mpg}$, respectively.

From these results, it became clear that the vehicle was setup lean following Mogas's set-up instructions. IGT did not attempt to optimize the emission results during setup. However, the results do indicate that $\mathrm{NO}_{\mathrm{x}}$ emissions could be reduced if run richer, and thereby increasing carbon monoxide emissions which are currently significantly below the limit. It should be noted that for the 10th percentile gas, the system did not pass the $1993 \mathrm{EPA} \mathrm{NO}_{\mathrm{x}}$ limit of $1.0 \mathrm{gr} . / \mathrm{mile}$.

The test results for the Impco system are presented in Table 7. For the mean natural gas composition fuel, the weighted total hydrocarbons (using a methane calibration) were 1.01 and 1.03 , methane was 1.11 and 1.01 , non-methane hydrocarbons were reported as 0.04 and 0.05 , carbon monoxide 0.80 and 0.54 , nitrous oxides 0.82 and 0.83 , and carbon dioxide 379 and 376 , respectively reported in grams per mile. Fuel economy for the tests were $18.1 \mathrm{mpg}$ and $18.2 \mathrm{mpg}$, respectively. For the 90th percentile natural gas composition fuel, the weighted total hydrocarbons were 1.04 and 0.97 , methane was 1.03 and 1.10 , non-methane hydrocarbons were reported as 0.05 and 0.04 , carbon monoxide 1.74 and 1.31 , nitrous oxides 0.57 and 0.63 , and carbon dioxide 378 and 373 , respectively reported in grams per mile. Fuel economy for the tests were $17.8 \mathrm{mpg}$ and $18.0 \mathrm{mpg}$, respectively. For the 10 th percentile natural gas composition fuel, the weighted total hydrocarbons were 1.65 and 1.79 , methane was 1.63 and 1.82 , non-methane hydrocarbons were 0.14 and 0.14 , carbon monoxide 0.02 and 0.02 , nitrous oxides 0.70 and 0.76 , and carbon dioxide 374 and 387, respectively reported in grams per mile. Fuel economy for the tests were $19.7 \mathrm{mpg}$ and $19.0 \mathrm{mpg}$, respectively.

As was the case with the Mogas system, the test results indicate that the vehicle was setup lean following Impco's setup instructions. IGT did not attempt to optimize the emission results during set-up. Again, the results indicate that $\mathrm{NO}_{\mathrm{X}}$ emissions could be reduced if run richer, and thereby increasing carbon monoxide emissions which are currently significantly below the limit. 
TABLE 6. MOGAS SYSTEM EMISSIONS SUMMARY

Fuel Type

Vehicle Odometer, miles

Exhaust Emission Results

Weighted Total, grams / mile

THC $\left(\mathrm{CH}_{4}\right.$ calibration)

$\mathrm{CH}_{4}$ (a)

NMHC (a)

$\mathrm{CO}$

$\mathrm{NO}_{\mathrm{x}}$

$\mathrm{CO}_{2}$

Fuel Economy, MPG

Fuel Type

Vehicle Odometer, miles

Exhaust Emission Results

Weighted Total, grams / mile $\mathrm{THC}\left(\mathrm{CH}_{4}\right.$ calibration) $\mathrm{CH}_{4}$ (a)

NMHC (a)

$\mathrm{CO}$

$\mathrm{NO}_{\mathrm{x}}$

$\mathrm{CO}_{2}$

Fuel Economy, MPG

Fuel Type

Vehicle Odometer, miles

Exhaust Emission Results

Weighted Total, grams / mile

$\mathrm{THC}\left(\mathrm{CH}_{4}\right.$ calibration)

$\mathrm{CH}_{4}$ (a)

NMHC (a)

$\mathrm{CO}$

$\mathrm{NO}_{\mathrm{x}}$

$\mathrm{CO}_{2}$

Fuel Economy, MPG
Mean CNG

6821

6832

1.41

1.42

1.40

1.41

0.16

0.11

0.39

0.19

0.85

363

18.9

0.90

357

19.1

90th Percentile CNG

6858

6869

1.28

1.37

1.22

1.34

0.16

0.09

0.59

0.28

0.79

0.83

$351 \quad 355$

19.2

19.0

10th Percentile CNG

6898

6910

1.72

1.98

1.66

2.00

0.17

0.18

0.12

0.13

1.03

1.01

355

359

20.7

(a) CNG Tests: Methane concentration for NMHC (non-methane hydrocarbon) calculation is based on GC speciation analysis. 


\section{TABLE 7. IMPCO SYSTEM EMISSIONS SUMMARY}

Fuel Type

Vehicle Odometer, miles

Exhaust Emission Results

Weighted Total, grams / mile

THC $\left(\mathrm{CH}_{4}\right.$ calibration)

$$
\mathrm{CH}_{4} \text { (a) }
$$

NMHC (a)

$\mathrm{CO}$

$\mathrm{NO}_{\mathrm{X}}$

$\mathrm{CO}_{2}$

Fuel Economy, MPG

Fuel Type

Vehicle Odometer, miles

Exhaust Emission Results

Weighted Total, grams / mile

THC $\left(\mathrm{CH}_{4}\right.$ calibration $)$

$$
\mathrm{CH}_{4} \text { (a) }
$$

NMHC (a)

$\mathrm{CO}$

$\mathrm{NO}_{\mathrm{x}}$

$\mathrm{CO}_{2}$

Fuel Economy, MPG

Fuel Type

Vehicle Odometer, miles

Exhaust Emission Results

Weighted Total, grams / mile

THC $\left(\mathrm{CH}_{4}\right.$ calibration)

$$
\mathrm{CH}_{4} \text { (a) }
$$

NMHC (a)

$\mathrm{CO}$

$\mathrm{NO}_{\mathrm{x}}$

$\mathrm{CO}_{2}$

Fuel Economy, MPG
Mean CNG

7309

7320

1.01

1.03

1.11

1.01

0.04

0.05

0.80

0.54

0.82

379

18.1

0.83

376

18.2

90th Percentile CNG

7280

7291

1.04

0.97

1.03

1.10

0.05

0.04

1.74

1.31

0.57

0.63

378

373

17.8

18.0

10th Percentile CNG

7251

7262

1.65

1.79

1.63

1.82

0.14

0.14

0.02

0.02

0.70

0.76

374

387

19.7

19.0

(a) CNG Tests: Methane concentration for NMHC (non-methane hydrocarbon) calculation is based on GC speciation analysis. 
However, the system met all applicable 1993 EPA emission standards for the entire range of natural gas compositions tested.

The test results for the GFI system are presented in Table 8. For the mean natural gas fuel, weighted total hydrocarbons using a methane calibration were 1.31 and 1.21 , methane was 1.30 and 1.26 , non-methane hydrocarbons were reported as 0.08 and 0.07 , carbon monoxide 4.16 and 3.92 , nitrous oxides 0.18 and 0.22 , and carbon dioxide 389 and 394, respectively reported in grams per mile. Fuel economy for the tests were $17.3 \mathrm{mpg}$ and $17.1 \mathrm{mpg}$, respectively. From these results, it became clear that the vehicle was setup rich by the GFI software. The average of the carbon monoxide values $(4.04 \mathrm{~g} / \mathrm{mile})$ was above the $3.4 \mathrm{gr} . / \mathrm{mile}$ EPA limit. However, the results indicate that $\mathrm{CO}$ emissions could be reduced if run leaner, and thereby increasing NOx emissions which are currently significantly below the limit. Since the software version supplied by GFI is specific to the 1993 Lumina tested, software changes may be required to "re-calibrate" the vehicle.

The two 90th percentile gas compositions tests indicated weighted total hydrocarbons of 1.27 and 0.77 , methane was 1.20 and 0.79 , non-methane hydrocarbons were reported as 0.07 and 0.05 , carbon monoxide 4.27 and 2.56 , nitrous oxides 0.22 and 0.19 , and carbon dioxide 373 and 378 , respectively reported in grams per mile. Fuel economy for the tests were $17.8 \mathrm{mpg}$ and $17.7 \mathrm{mpg}$, respectively. The two 10 th percentile gas compositions tests indicated weighted total hydrocarbons of 1.05 and 1.04, methane was 1.07 and 1.01 , non-methane hydrocarbons were reported as 0.08 and 0.07 , carbon monoxide 3.40 and 3.16 , nitrous oxides 0.23 and 0.19 , and carbon dioxide 395 and 377 , respectively reported in grams per mile. Fuel economy for the tests were $18.5 \mathrm{mpg}$ and $19.4 \mathrm{mpg}$, respectively. These results further confirmed that the vehicle was setup rich by the GFI software. However, a closer analysis of the test results by IGT indicated that the 90th percentile and the 10th percentile gas composition tests did not concur with the repeatability guidelines set forth in the publication "Statistical Design and Analysis Methods for the Auto/Oil Air Quality Research Program" as published by Painter and Rutherford in SAE paper 920319.3

Of the tests reported, the $\mathrm{HC}, \mathrm{CO}$, and $\mathrm{NO}_{\mathrm{x}}$ cold stabilized test pairs and the $\mathrm{HC}$ weighted total values from the 90th percentile gas composition did not meet this criteria. Likewise for the tests conducted on 10th percentile gas composition, the $\mathrm{NO}_{\mathrm{x}}$ and $\mathrm{HC}$ cold transient test pairs and the $\mathrm{HC}, \mathrm{CO}$, and $\mathrm{NO}_{\mathrm{x}}$ hot transient pairs were also above the limiting ratios. Further investigation indicated that an "air leak" in the testing equipment may have been a contributing cause to these differences.

As a result of the noted discrepancy, a third test was performed for the 90th and 10th percentile gas compositions to verify that the "air leak" was corrected and to provide further correlation of the test results. The data for these additional tests are summarized in Table 8 along with the previous test data. As can be seen, the 90th and 10th percentile "third" test data correlate to the "first" tests performed on each composition. However, based on the Auto/Oil reference cited above, none of the runs qualify as "other" which would require the entire test to be rejected. For this reason IGT took the recommended approach of averaging the three tests for the average values reported for the 90 th and 10 th percentile gas composition tests. 
TABLE 8. GFI SYSTEM EMISSIONS SUMMARY

Fuel Type

Vehicle Odometer, miles

Exhaust Emission Results

Weighted Total, grams / mile THC $\left(\mathrm{CH}_{4}\right.$ calibration $)$ $\mathrm{CH}_{4}$ (a)

NMHC (a)

$\mathrm{CO}$

$\mathrm{NO}_{\mathrm{x}}$

$\mathrm{CO}_{2}$

Fuel Economy, MPG

Fuel Type

Vehicle Odometer, miles

Exhaust Emission Results

Weighted Total, gr. / mile THC $\left(\mathrm{CH}_{4}\right.$ calibration $)$

$\mathrm{CH}_{4}$ (a)

NMHC (a)

$\mathrm{CO}$

$\mathrm{NO}_{\mathrm{x}}$

$\mathrm{CO}_{2}$

Fuel Economy, MPG

Fuel Type

Vehicle Odometer, miles

Exhaust Emission Results

Weighted Total, gr. / mile

$\mathrm{THC}\left(\mathrm{CH}_{4}\right.$ calibration)

$\mathrm{CH}_{4}$ (a)

NMHC (a)

$\mathrm{CO}$

$\mathrm{NO}_{\mathrm{x}}$

$\mathrm{CO}_{2}$

Fuel Economy, MPG
Mean CNG

7620

7630

1.31

1.21

1.30

1.26

0.08

0.07

4.16

3.92

0.18

0.22

389

394

17.3

17.1

90th Percentile CNG

7650

7661

7854

1.27

0.77

1.18

1.20

0.79

1.36

0.07

0.05

0.05

4.27

2.56

4.05

0.22

0.19

0.27

373

378

382

17.8

17.7

17.4

10th Percentile CNG

7691

7710

7873

1.05

1.04

1.00

1.07

1.01

1.02

0.08

0.07

0.07

3.40

3.16

3.36

0.23

0.19

0.26

395

377

386

18.5

19.4

18.9

(a) CNG Tests: Methane concentration for NMHC (non-methane hydrocarbon) calculation is based on GC speciation analysis. 
Using on the average values for each of the gas compositions, the GFI system failed the CO emissions test based on the $1993 \mathrm{CO}$ standard of $3.4 \mathrm{~g} / \mathrm{mi}$. The related NOx emission values and the system setup requirements and system sophistication are two factors to consider when assessing the GFI system. Unlike the previous two systems tested, the GFI system requires information about the gas composition during vehicle setup and calibration. For this test IGT, used the system default values and did not attempt to "dial in" the gas composition for each of the three tested gas compositions. Since the other two systems were not "tuned" on each composition, it was decided that this would give the GFI system an advantage. Second, and even more important, unlike the other systems, the GFI system incorporates a built-in learning algorithm in the electronic controls which gradually adjusts the fuel/gas mixture in response to operating parameters such as exhaust oxygen sensor output relative to load. This learning adjustment occurs gradually during normal driving. However, due to the nature of the emission testing, the vehicle was not driven between tests to allow the system to adjust to the new fuel composition. Because of the cost of the certified test fuel, driving between tests was not practical. Since the GFI system incorporates an adaptive learning electronic control system, this system may have been able to pass all of the emission standards, if given enough time on a given gas composition. It is IGT's recommendation that the adaptive learning system of this product be further investigated to determine the speed of learning as well as adaptive range.

The test results for the ANGI system are presented in Table 9. For the mean natural gas composition fuel, the weighted total hydrocarbons (using a methane calibration) were 0.52 and 0.50 , methane was 0.49 and 0.52 , non-methane hydrocarbons were reported as 0.04 and 0.03 , carbon monoxide 1.40 and 1.29 , nitrous oxides 0.11 and 0.12 , and carbon dioxide 384 and 385 , respectively reported in grams per mile. Fuel economy for the tests were $17.9 \mathrm{mpg}$ and $17.8 \mathrm{mpg}$, respectively. For the 90th percentile natural gas composition fuel, the weighted total hydrocarbons were 0.78 and 0.54 , methane was 0.82 and 0.53 , non-methane hydrocarbons were reported as 0.04 and 0.03 , carbon monoxide 5.05 and 1.95 , nitrous oxides 0.09 and 0.18 , and carbon dioxide 397 and 392, respectively reported in grams per mile. Fuel economy for the tests were $16.7 \mathrm{mpg}$ and $17.2 \mathrm{mpg}$, respectively. For the 10th percentile natural gas composition fuel, the weighted total hydrocarbons were 0.92 and 0.92 , methane was 0.94 and 1.06 , non-methane hydrocarbons were 0.06 and 0.06 , carbon monoxide 0.23 and 0.24 , nitrous oxides 1.09 and 1.46 , and carbon dioxide 387 and 428 , respectively reported in grams per mile. Fuel economy for the tests were $19.1 \mathrm{mpg}$ and $17.2 \mathrm{mpg}$, respectively.

From weighted total results for the mean gas composition, the average levels of $\mathrm{CO}$ and $\mathrm{NOX}$ emissions are well below the current EPA limits. The weighted totals for the 10th percentile composition indicate that the ANGI system failed the current $\mathrm{NO}_{\mathrm{x}}$ standard of $1.0 \mathrm{~g} / \mathrm{mile}$. This indicates that the system produced very low emission levels with the mean composition gas, but the 10 th percentile composition caused the system to run too lean.

The test results for the 90th percentile gas composition for the levels of $\mathrm{CO}$ did not concur with the repeatability guidelines set forth in the Auto/Oil reference. Again, based on Auto/Oil recommendations, a third test was performed. The results of the second and third tests were within recommended limits. Since AutoResearch Labs. indicated that other ongoing tests may have contributed to high background levels of $\mathrm{CO}$ during the first test and since the second and third 


\section{TABLE 9. ANGI SYSTEM EMISSIONS SUMMARY}

Fuel Type

Vehicle Odometer, miles

Exhaust Emission Results

Weighted Total, grams / mile

THC $\left(\mathrm{CH}_{4}\right.$ calibration $)$

$$
\mathrm{CH}_{4} \text { (a) }
$$

NMHC (a)

$\mathrm{CO}$

$\mathrm{NO}_{\mathrm{x}}$

$\mathrm{CO}_{2}$

Fuel Economy, MPG

\section{Fuel Type}

Vehicle Odometer, miles

Exhaust Emission Results

Weighted Total, g/ mile

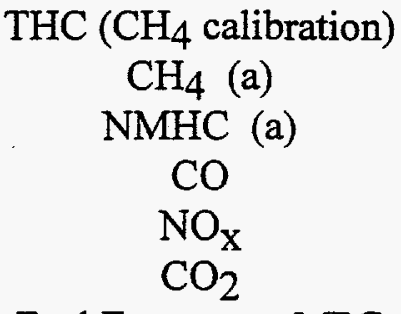

Fuel Economy, MPG

Fuel Type

Vehicle Odometer, miles

Exhaust Emission Results

Weighted Total, g/mile

$\mathrm{THC}\left(\mathrm{CH}_{4}\right.$ calibration)
$\mathrm{CH}_{4}$ (a)
$\mathrm{NMHC}^{(\mathrm{a})}$
$\mathrm{CO}$
$\mathrm{NO}_{\mathrm{x}}$
$\mathrm{CO}_{2}$

Fuel Economy, MPG
Mean CNG

$8610 \quad 8621$

$0.52 \quad 0.50$

$0.49 \quad 0.52$

$0.04 \quad 0.03$

$1.40 \quad 1.29$

$0.11 \quad 0.12$

$384 \quad 385$

$17.9 \quad 17.8$

90th Percentile CNG

$8670 \quad 8681 \quad 8808$

$\begin{array}{lll}0.78 & 0.54 & 0.56 \\ 0.82 & 0.53 & 0.58 \\ 0.04 & 0.03 & 0.05 \\ 5.05 & 1.95 & 1.60 \\ 0.09 & 0.18 & 0.10 \\ 397 & 392 & 394 \\ 16.7 & 17.2 & 17.1\end{array}$

10th Percentile CNG

$8632 \quad 8651$

$0.92 \quad 0.92$

$0.94 \quad 1.06$

$0.06 \quad 0.06$

$0.23 \quad 0.24$

$1.09 \quad 1.46$

$387 \quad 428$

$19.1 \quad 17.2$

(a) CNG Tests: Methane concentration for NMHC (non-methane hydrocarbon) calculation is based on GC speciation analysis. 
test results were in close agreement, the first test was treated as an outlier and the average results were taken from tests 2 and 3. Thus, the weighted total test results for the 90 th percentile were well within the EPA limits for $\mathrm{CO}$ and $\mathrm{NO}_{\mathrm{x}}$. This indicates that the ANGI system's fuel management and feedback system operates well on the mean and 90th percentile compositions which have a higher methane content, but the system did not adjust itself properly and failed current EPA limits on $\mathrm{NO}_{\mathrm{x}}$ emission levels when operating with 10 th percentile gas composition fuel.

After all the conversion systems had been fully tested, IGT removed the last conversion system from the vehicle and returned the vehicle to as close as possible to its original gasoline fueled state. The vehicle was then subjected to a final set of emission tests running on indolene. These tests were performed to ensure that the vehicle was not altered in such a way as to have affected the natural gas conversion system tests. The results of the concluding set of indolene tests are presented in Table 10. As can be seen, the results of the first test indicated that carbon monoxide levels were extremely high in the Hot Transient Phase and the vehicle failed the emission test. After this test, IGT re-inspected the vehicle to determine if anything had been overlooked in the conversion back to dedicated gasoline operation. Failing to discover any obvious conversion oversights, the vehicle was tested again. In the second test the carbon monoxide total was still too high, although significantly below the previous value.

\section{Conclusions}

A summary of the test results are presented in Figures 3 through 7 . As can be seen from these results, the Mogas system produced the lowest carbon monoxide test results followed by the Impco, ANGI and GFI systems. The GFI system actually failed the CO emissions test based on the $1993 \mathrm{CO}$ standard of $3.4 \mathrm{~g} / \mathrm{mi}$. However, two factors must be taken into consideration when assessing the GFI system. Unlike the other 2 systems, the GFI system requires information about the gas composition during vehicle setup and calibration. For this test IGT used the system default values and did not attempt to "dial in" the gas composition for each of the three gas compositions tested. Since the other two systems were not "tuned" on each composition, it was decided that this would give the GFI system an advantage. Second, and even more important, unlike the other systems, the GFI system incorporates a built-in learning algorithm in the electronic controls which gradually adjusts the fuel/gas mixture in response to operating parameters such as exhaust oxygen sensor output relative to load. This learning adjustment occurs gradually during normal driving. However, due to the nature of the emission testing, the vehicle was not driven between tests to allow the system to adjust to the new fuel composition. Because of the cost of the certified test fuel, driving between tests was not deemed practical and would have established a different test protocol that would not have affected the other conversion systems.

With respect to the average $\mathrm{NO}_{\mathrm{x}}$ emission level, the GFI system produced the lowest $\mathrm{NO}_{\mathrm{x}}$ test results for all compositions followed by the Impco and Mogas systems. The ANGI system produced even lower levels of $\mathrm{NO}_{\mathrm{x}}$ emissions with the mean and 90th percentile gas compositions, but did not pass the $1993 \mathrm{NO}_{\mathrm{x}}$ standard of $1.0 \mathrm{~g} / \mathrm{mi}$. with the 10 th percentile gas composition fuel. The Impco and GFI systems passed the $\mathrm{NO}_{\mathrm{x}}$ standard while the Mogas system was slightly over 
TABLE 10. FINAL EXHAUST AND EVAPORATIVE INDOLENE EMISSIONS DATA

Test Fuel
Vehicle Odometer, miles
Exhaust Emission Results

Cold Transient, grams

THC $\left(\mathrm{C}_{3} \mathrm{H}_{8}\right.$ calibration)

$\mathrm{CH}_{4}$ (a)

NMHC (a)

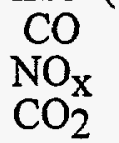

Fuel Economy, MPG

Cold Stabilized, grams

THC $\left(\mathrm{C}_{3} \mathrm{H}_{8}\right.$ calibration) $\mathrm{CH}_{4}$ (a)

$\mathrm{NMHC}(\mathrm{a})$

$\mathrm{CO}$

$\mathrm{NO}_{\mathrm{x}}$

$\mathrm{CO}_{2}$

Fuel Economy, MPG

Hot Transient, grams

THC ( $\mathrm{C}_{3} \mathrm{H}_{8}$ calibration)

$\mathrm{CH}_{4}$ (a)

NMHC (a)

$\mathrm{CO}$

$\mathrm{NO}_{\mathrm{x}}$
$\mathrm{CO}_{2}$

Fuel Economy, MPG

Weighted Total, grams / mile

THC ( $\mathrm{C}_{3} \mathrm{H}_{8}$ calibration) $\mathrm{CH}_{4}$ (a)

NMHC (a)

$$
\begin{aligned}
& \mathrm{CO} \\
& \mathrm{NO}_{\mathrm{x}} \\
& \mathrm{CO}_{2}
\end{aligned}
$$

Fuel Economy, MPG
Indolene Indolene

$8491 \quad 9060$

(b)

3.14

0.26

2.84

44.62

4.32

1715

17.8

(c)

4.07

0.31

3.71

41.35

4.66

1775

17.3

0.64

0.19

0.41

10.50

1.20

1987

17.1

0.44

0.17

0.24

6.95

1.66

1985

17.2

1.36

0.24

1.08

38.36

1.25

1478

20.7

0.78

0.17

0.58

7.47

2.40

1492

21.2

0.37

0.35

0.06

0.30

6.93

0.51

479

18.1

0.05

0.29

3.89

0.68

483

18.2

Shed, grams

Diurnal

0.32

0.14

0.22

0.18

Total

0.46

0.40

(a) CNG Tests: Methane concentration is based on independent $\mathrm{GC}$ analysis. NMHC calculation from GC speciation analysis.

(b) Reported very high $\mathrm{CO}$, especially during Hot Transient phase.

(c) Following high $\mathrm{CO}$ investigation by IGT. 


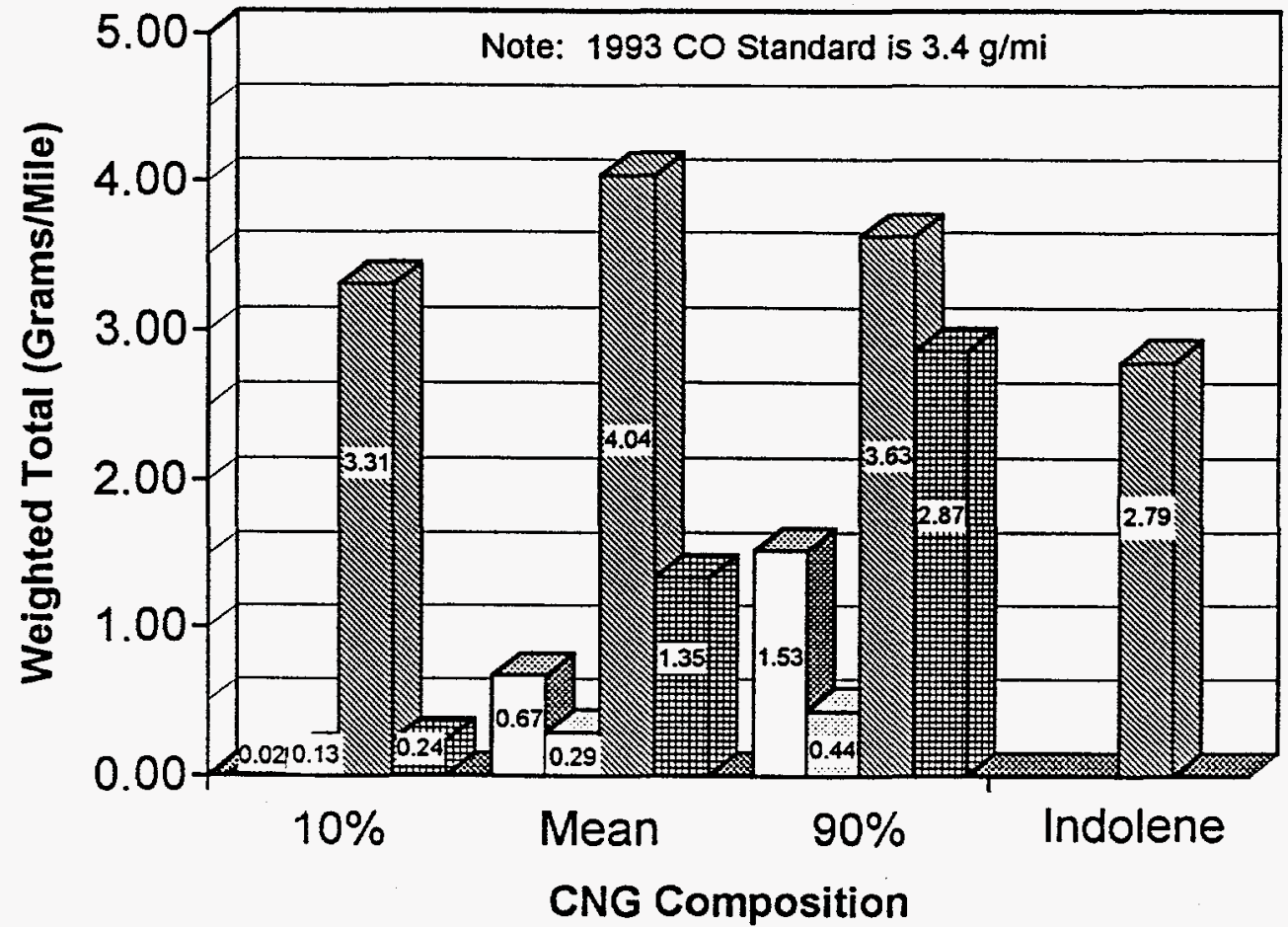

Figure 3. Carbon Monoxide Emission Test Results

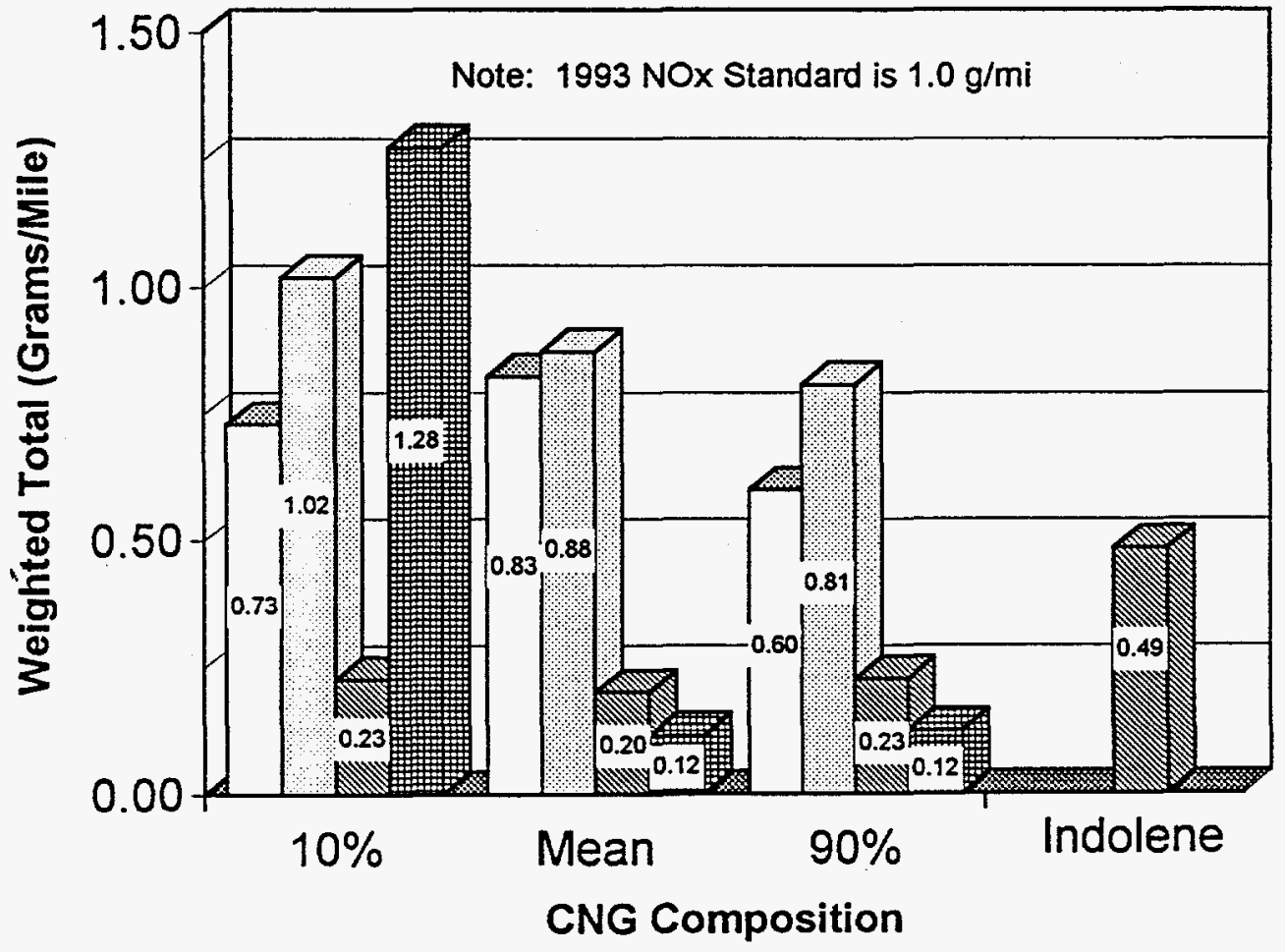

Figure 4. Nitrogen Oxide Emission Test Results

\begin{tabular}{|l|}
\hline 口IMPCO \\
$\square$ MOGAS \\
⿴囗十AI \\
\hline
\end{tabular}

口IMPCO MOGAS $\mathbb{Q} \mathrm{GFI}$ TANGI 


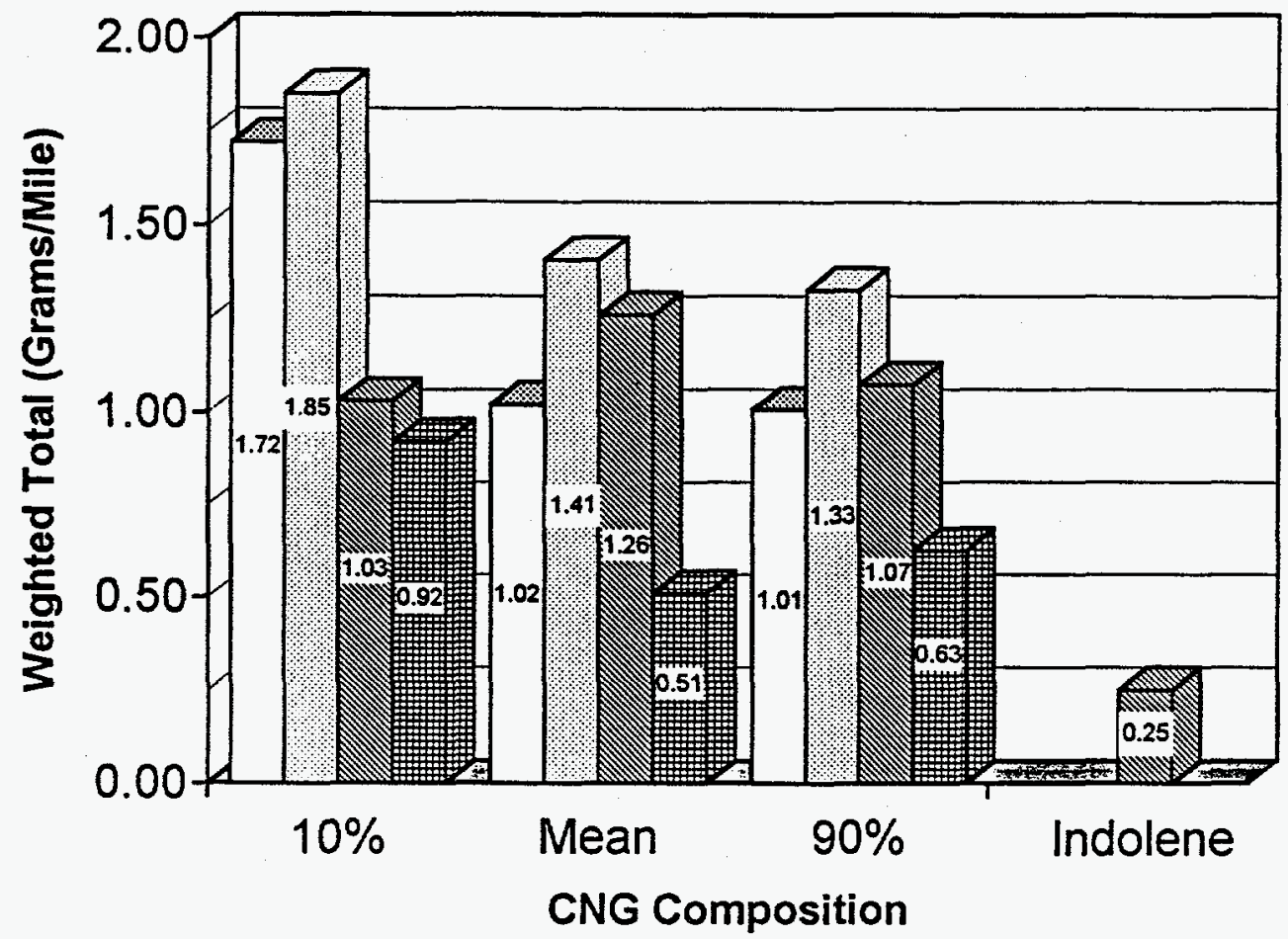

Figure 5. Total Hydrocarbon Emission Test Results

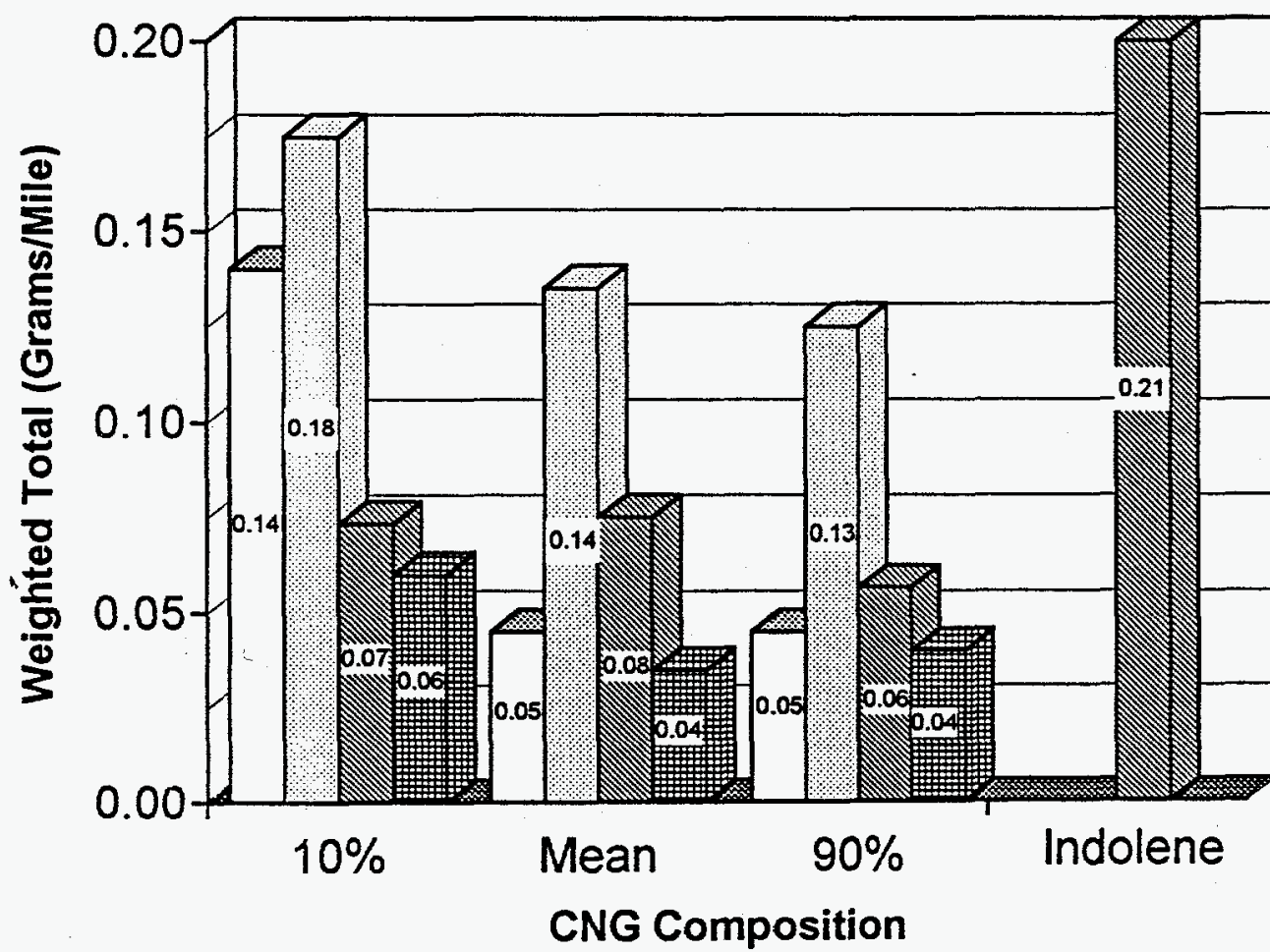

Figure 6. Non-methane Hydrocarbons Emission Test Results
DIMPCO $\square$ MOGAS $\mathbb{Q} \mathrm{GFI}$ דANGI

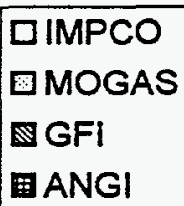




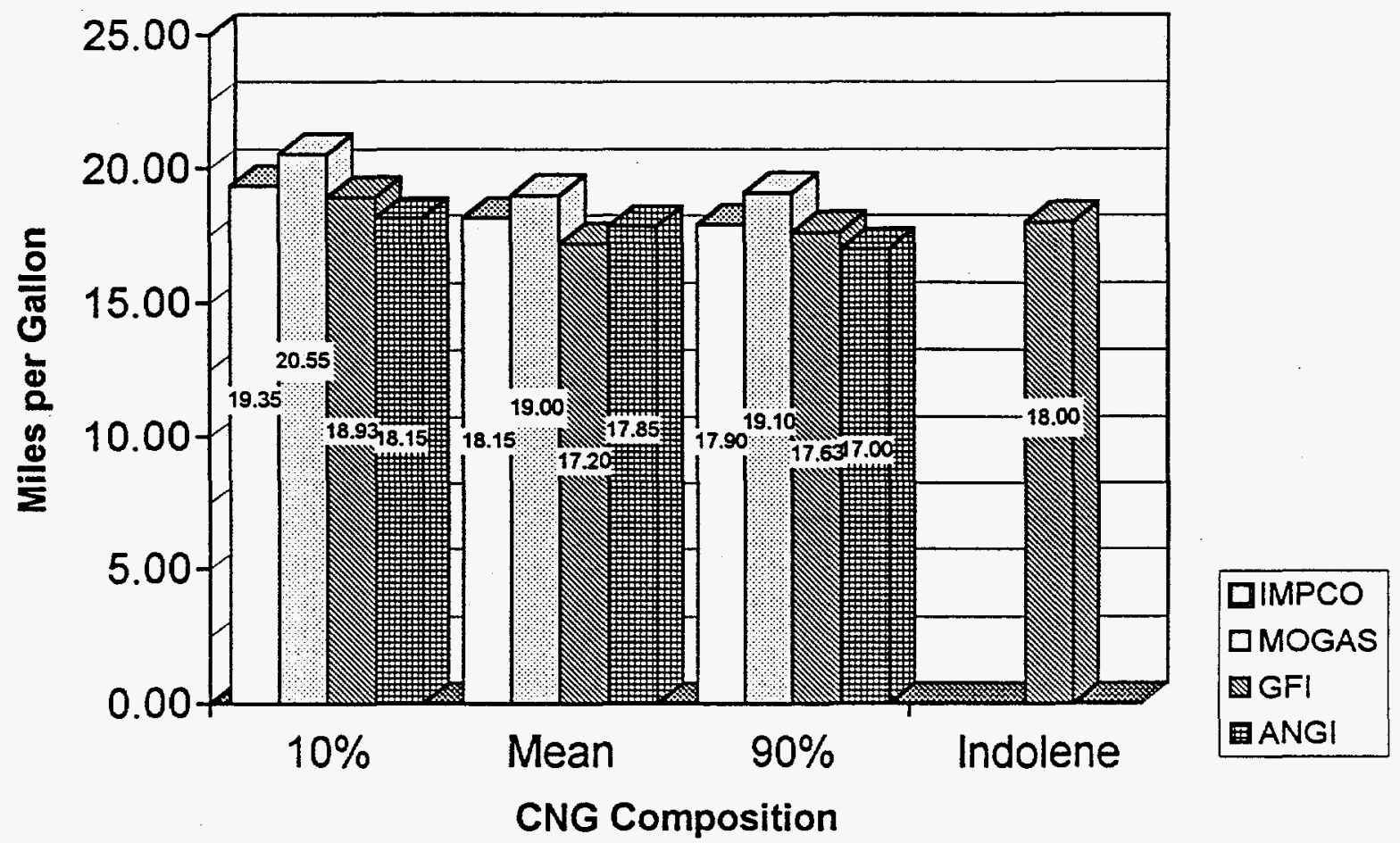

Figure 7. Fuel Economy Test Results 
the limit. The system setup procedure must be considered when assessing these results. Both the Impco, and Mogas systems involved subjective tuning of the system to achieve low tailpipe emissions based on the use of a 4 gas analyzer. The subjective nature of the setup as well as the system sensitivity resulted in a lean mixture for all three of these conversion systems. This produced a combination of relatively low $\mathrm{CO}$ and high $\mathrm{NO}_{\mathrm{x}}$, as would be expected. On the other hand, the GFI and ANGI systems calibrate themselves automatically, producing the opposite effect. This automatic rich setup produced surprisingly consistent low $\mathrm{NO}_{\mathrm{x}}$ values for each of the gas compositions tested, resulting in $\mathrm{NO}_{x}$ emissions below both the 1993 and 1994 emission limits, except where noted above.

The only observation IGT could draw from the final indolene tests was that the vehicle had been extensively modified during the four different conversions. These modifications affected the final conversion back to gasoline. Within the scope of this study, further investigation into this issue was not warranted. Therefore, conversion system emission results should only be compared to the initial indolene emission values.

In addition to the specific conclusions about the characteristics of each of the conversion systems noted above, a number of general conclusions have been made about the project and the concept of testing $\mathrm{CNG}$ conversion kits.

The first conclusion is that there are a number of conversion kits that have had limited evaluation, and often with unknown gas compositions. The results of this study indicate that gas composition can impact emission results. Clearly, each of the systems tested could pass emission tests for a given fuel composition. However, none of the systems tested could pass all of the emission standards running on all of the fuels. For installers in the field using know gas compositions or tuning the vehicle of gas normally found in the vehicles operating area, one can speculate that all of the systems when properly installed could pass all emission standards. However, when gas compositions change dramatically from the composition used to tune the initial installation, the vehicles may fail one or more of the emission standards.

The results of this project also clearly indicate that conversion systems have to be calibrated for a given vehicle type and engine family. Without integration into the existing on-board computer and diagnostic system, all of the conversion systems would not perform properly. Therefore, the concept of a "generic" conversion system does not exist. In conclusion, the following observations can be made:

1. All of the conversion systems could pass emission tests on at least one of the natural gas compositions tested.

2. None of the conversion systems could pass all of the emission test requirements on all three compositions of natural gas.

3. Each conversion system must be "tuned" using a gas composition similar to the fuel which it will operate on for optimal emission results.

4. Each conversion system must be calibrated for a specific vehicle and engine family. A "generic" system cannot be made to adopt to a broad range of vehicles or engine types. 


\section{Recommendations}

Dramatic changes in natural gas composition can adversely affect vehicle emissions. Therefore, an analysis of the regional variability of natural gas should be undertaken. This will indicate the likelihood of a vehicle encountering large shifts in fuel composition. Adaptive learning systems incorporated into conversion systems may overcome this problem in areas of high fuel composition variability. However, further research is needed to verify the effectiveness of adaptive learning systems as implemented on certain conversion systems.

Many other systems, not tested as part of this research effort, also show promise in their stated capabilities. These include systems such as MESA Environmental GEMS system, the Fuel Pilot system, and the Synchro-Start / DAI "Translator" system to name a few. As additional systems are developed (a certainty based on the emphasis on alternative fueling) and as current systems are substantially improved, additional testing would be warranted to determine each of the system's suitability for use and its ability to meet the intended functions of the conversion.

A more detailed analysis is also warranted to understand the different emission components in the exhaust of a converted vehicle. Specifically, complete speciation analysis should be performed for new systems to fully determine their emissions impact.

The final recommendation is that basic research should be performed for conversion systems in general. This could involve fuel metering and gas composition sensor research. Although each of the tested kits proved adequate, none significantly reduced the vehicle's emissions, even though natural gas has proven itself as an ultra low emissions vehicle (ULEV) fuel based on OEM dedicated vehicle emission tests. New systems currently under development show promise in further reducing emission levels. Research is still required to understand the complexities of the conversion process, and fine-tuning is necessary to further reduce emissions. The target should be the development of a suitable conversion system that results in an ultra-low emission vehicle. 


\section{References}

1. Liss, W.L., Thrasher, W.H., Steinmetz, G.F., Chowdiah, P., and Attari, A., "Variability of Natural Gas Composition in Select Metropolitan Areas of the United States," Gas Research Institute Report No. GRI-92/0123; March 1992.

2. "1990 CRC Driveability Workshop," CRC Report No. 577, October, 1990.

3. Painter, L.J. and Rutherford, J.A., "Statistical Design and Analysis Methods for the Auto/Oil Air Quality Research Program," SAE Paper 920319, SP-920.

\section{Bibliography}

"Compressed Gas And Compressed Air Equipment," Subpart M, 29 CFR Ch. XVIII (7-1-91 Edition), pgs. 465-466.

"Compressed Natural Gas (CNG) Vehicular Fuel Systems," 1992 Edition, NFPA 52, pgs. 52-5 to $52-25$.

"Recommended Practice for Compressed Natural Gas Vehicle Fuel," Society of Automotive Engineers, J1616 (Draft).

King, S.R., "The Impact of Natural Gas Composition on Fuel Metering and Engine Operational Characteristics," SAE Paper 920593 presented at the International Congress and Exposition, Detroit, Michigan, February 24-28, 1992

Raine, R.R. and Jones, G.M., "Comparison of Temperatures Measured In Natural Gas and Gasoline Fueled Engines," SAE Paper 901503 presented the Future Transportation Technology Conferences and Exposition, San Diego, CA, August 13-16, 1990. 


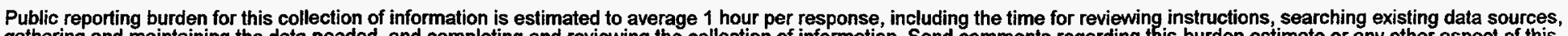

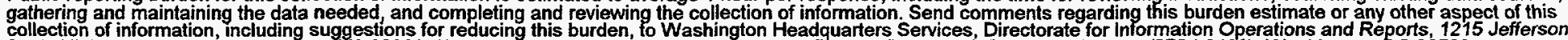

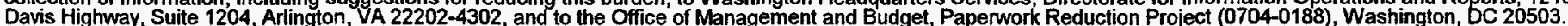

\begin{tabular}{|l|l|l|}
\hline 1. AGENCY USE ONLY (Leave blank) & $\begin{array}{l}\text { 2. REPORT DATE } \\
\text { July } 1995\end{array}$ & $\begin{array}{l}\text { 3. REPORT TYPE AND DATES COVERED } \\
\text { Subcontract Report }\end{array}$ \\
\hline
\end{tabular}

\section{TITLE AND SUBTITLE}

Evaluation of Aftermarket CNG Conversion Kits in Light-Duty Vehicle Applications

6. AUTHOR(S)

C.F. Blazek, P. Freeman Rowley, J.W. Grimes

7. PERFORMING ORGANIZATION NAME(S) AND ADDRESS(ES)

Institute of Gas Technology

4201 West 36th Street

Chicago, IL 60632-3898

9. SPONSORING/MONITORING AGENCY NAME(S) AND ADDRESS(ES)

National Renewable Energy Laboratory

1617 Cole Boulevard

Golden, CO 80401-3393

\section{FUNDING NUMBERS}

(C) $\mathrm{W}-2-12120-1$

(TA) FU521010

8. PERFORMING ORGANIZATION REPORT NUMBER

NA

10. SPONSORINGMONITORING AGENCY REPORT NUMBER

NREL/TP-425-6550

\section{SUPPLEMENTARY NOTES}

12a. DISTRIBUTION/AVAILABILITY STATEMENT

National Technical Information Service

U.S. Department of Commerce

5285 Port Royal Road

Springfield, VA 22161 12b. DISTRIBUTION CODE

UC-1504

\section{ABSTRACT (Maximum 200 words)}

This document evaluates three compressed natural gas conversion systems using a 1993 Chevrolet Lumina baseline vehicle. A fourth conversion system was added to the test matrix through funding support from Brooklyn Union. The objective of this project was to measure the Federal Test Procedure emissions and fuel economy of different conversion systems, and to compare their performance to gasoline-fueled operation and each other
14. SUBJECT TERMS
15. NUMBER OF PAGES
33

compressed natural gas (CNG), conversion system, fuel composition, gas fractions, Wobbe number, specific gravity

16. PRICE CODE

17. SECURITY CLASSIFICATION OF REPORT
18. SECURITY CLASSIFICATION OF THIS PAGE
19. SECURITY CLASSIFICATION OF ABSTRACT
20. LIMITATION OF ABSTRACT

Standard Form 298 (Rev. 2-89) Prescribed by ANSI Std. Z39-18
NSN 7540-01-280-5500 